\title{
ECOBATIMETRIA E CARACTERÍSTICAS ACÚSTICAS DO LEITO OCEÂNICO NA REGIÃO DO CANAL DO ALBARDÃO - RIO GRANDE DO SUL - BRASIL
}

\author{
PAULA COSTA CAMPOS ${ }^{1,2}$, STEFAN CRUZ WEIGERT ${ }^{1,3}$, \& LAURO SAINT PASTOUS MADUREIRA ${ }^{1,4}$ \\ 1 Universidade Federal do Rio Grande (FURG)/ Instituto de Oceanografia. Av. Itália km $08 \mathrm{~s} / \mathrm{n}^{\circ} \mathrm{CP} 474$ Campus Carreiros Rio Grande, RS CEP \\ 96201-900. 2 - paula_no@yahoo.com; 3-docsw@furg.br.; 4 - doclsm@furg.br.
}

\section{RESUMO}

O canal do Albardão estende-se desde as proximidades de Punta del Este (Uruguai) até aproximadamente a latitude do Farol do Albardão (RS), sobre poços de lama que caracterizam antigos canais de drenagem do Rio da Prata. A partir de dados hidroacústicos coletados sobre a plataforma continental sul do Rio Grande do Sul, através de uma eco-sonda científica EK500 SIMRAD, com freqüência de $38 \mathrm{kHz}$, foram gerados perfis batimétricos com dados de dureza acústica do fundo. Foi verificado que a extensão média do canal na região amostrada foi de 12,7 milhas náuticas ( $\mathrm{mn}$ ), sendo seu comprimento cerca de $47 \mathrm{mn}$, ocupando uma área aproximada de $670 \mathrm{mn} 2(2.293,4 \mathrm{Km} 2)$. A análise estatística indica diferenças extremamente significativas entre os valores médios de dureza acústica, dentro $(-16,04 \mathrm{~dB})$ e fora $(-9,96 \mathrm{~dB})$ do canal, sendo que valores menores indicam uma menor dureza de fundo. Uma superfície 3D do canal demonstra a continuidade batimétrica do mesmo, ao contrário do que é apresentado na carta náutica ํㅜ임 da DHN.

PALAVRAS-CHAVE: ecobatimetria, hidroacústica, Rio da Prata, canal do Albardão.

\section{ABSTRACT \\ Echo-bathymetry and acoustic characteristics of oceanic bottom in the Albardão channel region Rio Grande do Sul - Brazil}

The Albardão channel extends from the proximities of Punta del Este (Uruguay) to approximately the Albardão Lighthouse latitude (Rio Grande do Sul, Brazil), on mud depressions related to the ancient Plata River drainage channels. Bathymetric profiles with Bottom Surface Backscattering Strenght (BSBS) information were produced using hydroacoustic data collected on the southern continental shelf of Rio Grande do Sul, using a scientific echo-souder EK500 SIMRAD, operating at the nominal frequency of $38 \mathrm{kHz}$. The mean channel width in the region is 12,7 nautical miles $(\mathrm{nm})$, and it's length about $47 \mathrm{~nm}$, occupying an area of approximately $670 \mathrm{~nm} 2(2.293,4 \mathrm{Km} 2)$. The statistical analysis indicates extremely significant differences between the average values of BSBS, inside $(-16,04 \mathrm{~dB})$ and outside $(-9,96 \mathrm{~dB})$ the channel, where lower values indicate softer bottom. A 3D surface of the channel shows it to be a continuous bathymetric feature, different from what is observed in the nautical chart No. 90 from DHN.

KEYWORDS: Albardão channel, echo-bathymetry, hydroacoustics, Plata River.

\section{INTRODUÇÃO}

A metodologia acústica é uma ferramenta que permite obter um grande volume de informações em ambientes submersos em um período relativamente curto de tempo. Dentre suas aplicações podem-se citar levantamentos batimétricos e identificação das características sedimentológicas do leito marinho (Mitson 1983).

O método consiste na transmissão de ondas sonoras que se propagam na coluna d'água, refletindo quando encontram obstáculos em sua trajetória. Os ecos de retorno são amplificados e digitalmente armazenados, podendo ser visualizados, em tempo real, em monitor ou registros em papel (MacLennan \& Simmonds 1992). Essas representações gráficas são denominadas ecogramas.

A energia refletida pela superfície do fundo é referida como BSBS (Bottom Surface Backscattering Strenght), ou força de retroespalhamento acústico da superfície do fundo, sendo proporcional à dureza acústica do substrato. Propriedades como composição química, características granulométricas, grau de compactação e presença de irregularidades morfológicas têm grande influência nesse parâmetro (Collins et al. 1996). Os dados de BSBS são disponibilizados em decibel (dB), correspondendo a uma relação logarítmica entre a energia incidente e a refletida pelo fundo.

O canal do Albardão, estende-se desde as proximidades de Punta del Este (Uruguai) até aproximadamente a latitude do Farol do Albardão (RS) e possivelmente mais ao norte, até a altura do Farol de Sarita, nas proximidades da latitude $32^{\circ} 40^{\prime} \mathrm{S}$ (Figueiredo \& Madureira 2004), orientado paralelamente à costa.

A parte interna do canal apresenta sedimentos lamosos, os quais separam dois corpos de areia (Laborde 1999). Essa faixa de sedimentos de textura síltico-argilosa, sobreposta a sedimentos de textura arenosa, localiza-se sobre os poços de lama que caracterizam antigos canais de drenagem do Rio da Prata (Corrêa 1987a, Corrêa 1987b, Corrêa et al. 1996). Figueiredo \& Madureira (2004) observaram distribuição sedimentológica similar para a área em estudo, relacionando dados de BSBS com o diagrama triangular modificado de Shepard (1979). 
Tomazelli (1978 apud Corrêa 1987a) classificando a Plataforma Continental do Rio Grande do Sul quanto à distribuição de minerais pesados, denominam a região de Província Platina, identificada pela assembléia mineralógica augita-hiperstênio. De acordo com o autor, tal fato corrobora a idéia de uma estreita relação com os sedimentos do Prata. Martins (1978) classifica essa área como Fácies Platina distal, também a relacionando à antiga drenagem do Rio da Prata que, durante o Pleistoceno, possuía maior influência na plataforma interna do Uruguai e Rio Grande do Sul.

Martins et al. (2003), referem-se ao pacote sedimentar como lamas relíquias, e afirmam que as mesmas são produto do deságüe do Rio da Prata em situação de nível de mar pré-trangressão holocênica.

Parece haver consenso na literatura quanto à composição sedimentar, bem como quanto à origem dos sedimentos síltico-argilosos presentes na região estudada. No entanto, no que se refere à idade do depósito, alguns autores defendem sua formação trangressiva holocênica (Kowsmann \& Costa 1979, Tomazelli 1978 apud Corrêa 1987a, Martins et al. 2003), enquanto Ayup (1987) sugere que tal faixa sedimentar é resultado do transporte atual de sedimentos finos por uma corrente de turbidez que se desloca através dos poços de lama.

\section{MATERIAL E MÉTODOS}

Os dados hidroacústicos foram obtidos em quatro cruzeiros de pesquisa dos Projetos Anchoita e Pronex (Convênios CNPq/FURG), realizados entre os anos de 2005 e 2007, a bordo do Navio Oceanográfico Atlântico Sul, da Universidade Federal do Rio Grande (FURG). O equipamento utilizado foi uma eco-sonda científica digital modelo EK500 SIMRAD, operando na freqüência de $38 \mathrm{kHz}$. Os dados foram armazenados como ecogramas digitais através do software Movies+/IFREMER v 3.1, e na forma de arquivos de texto (ASCII), denominados "telegramas", além de impressos em tempo real.

A análise dos ecogramas impressos e digitais permitiu identificar a presença do canal através do gradiente batimétrico. A partir desta constatação foram selecionados os dados acústicos dos setores mais próximos à área de interesse.
Para extração e organização dos dados para posterior processamento, foram utilizados "filtros" desenvolvidos em linguagem computacional Lua (http://www.lua.org/). Os parâmetros utilizados foram:

VL (hora, data, milha);

GL (hora, latitude, longitude); e

D1 (hora, profundidade, dureza).

Os dados foram validados e inseridos em um Sistema de Informações Geográficas (SIG ArcView/ESRI 3.1). Foi utilizada uma escala em tons de cinza para indicar diferenças em termos de classes de BSBS, sendo que cores mais claras representam fundos menos refletivos $e$, consequentemente, menos consolidados, ao passo que cores mais escuras representam fundos mais refletivos, associados a substratos mais consolidados.

Doze perfis batimétricos com indicação de dureza de fundo foram gerados utilizando o software Matlab 6.5/MATHWORKS.

Alguns perfis foram subdivididos para melhor visualização das irregularidades do fundo, alterando-se assim, a escala de profundidade e o exagero vertical. Com a intenção de manter um padrão, convencionouse o valor de $25 \mathrm{mn}$ à extensão dos sub-perfis, gerando de zero a três sub-perfis por perfil.

Os dados referentes aos perfis 1 a 6 foram classificados quanto à sua posição em relação ao canal do Albardão, como "dentro" e "fora", de acordo com as variações batimétricas, caracterizadas por aumento gradativo da profundidade em direção leste, nas proximidades da isóbata de $40 \mathrm{~m}$, e posterior redução da mesma voltando à valores próximos ao nível inicial. Tais variações batimétricas foram acompanhadas de um alargamento do registro de fundo, indicativo de substrato menos refletivo.

Para análise estatística dos dados de BSBS foram selecionados trechos dos perfis 1 à 6 , coletados ao longo de 1,0 mn correspondente à região mais profunda do canal, e 1,0 $\mathrm{mn}$ fora, sendo $0,5 \mathrm{mn}$ em direção ao continente e $0,5 \mathrm{mn}$ em direção à região oceânica, nas proximidades das margens.

Foi aplicada análise de comparação de médias de BSBS (ANOVA one-way) entre as posições dentro e fora do canal, através do software Statistica 6.0/STATSOFT. Além disso, foram gerados histogramas de distribuição de freqüência relativa dos valores de BSBS, para os trechos dentro e fora. 
Superfícies batimétricas foram geradas através da interpolação (método Kriging) dos dados de profundidade coletados pela sonda utilizando o software Surfer 8.0/GOLDEN SOFTWARE.

\section{RESULTADOS}

A análise dos perfis batimétricos indicou que o canal do Albardão é marcado por um aumento gradativo de até cerca de $30 \mathrm{~m}$ na profundidade local, relativamente aos trechos externos adjacentes. Essa depressão foi observada próximo à isóbata de $40 \mathrm{~m}$. A extensão média do canal na região prospectada foi de $12,7 \mathrm{mn}(23,5 \mathrm{~km})$.

Uma clara mudança no padrão dos ecoregistros de fundo identifica as margens, indicando uma menor dureza acústica de fundo dentro do canal, o que é próprio de um fundo coberto por sedimentos finos (figura 1). Essa alteração no padrão do ecoregistro é corroborada pelos dados de BSBS apresentados pela sonda, onde valores médios menores indicam uma menor dureza do fundo.

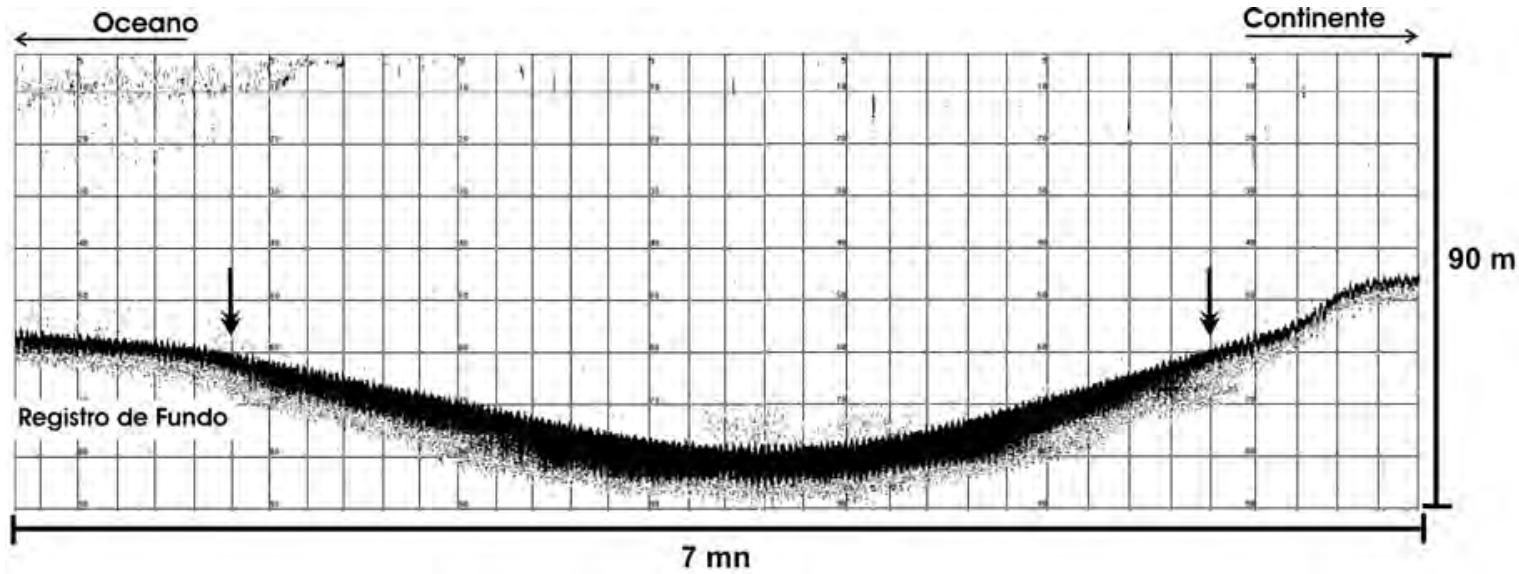

Figura 1: Eco-registro do canal do Albardão. As setas apontam as alterações nas características do registro de fundo, indicativas da posição das margens (exagero vertical de 144 vezes).

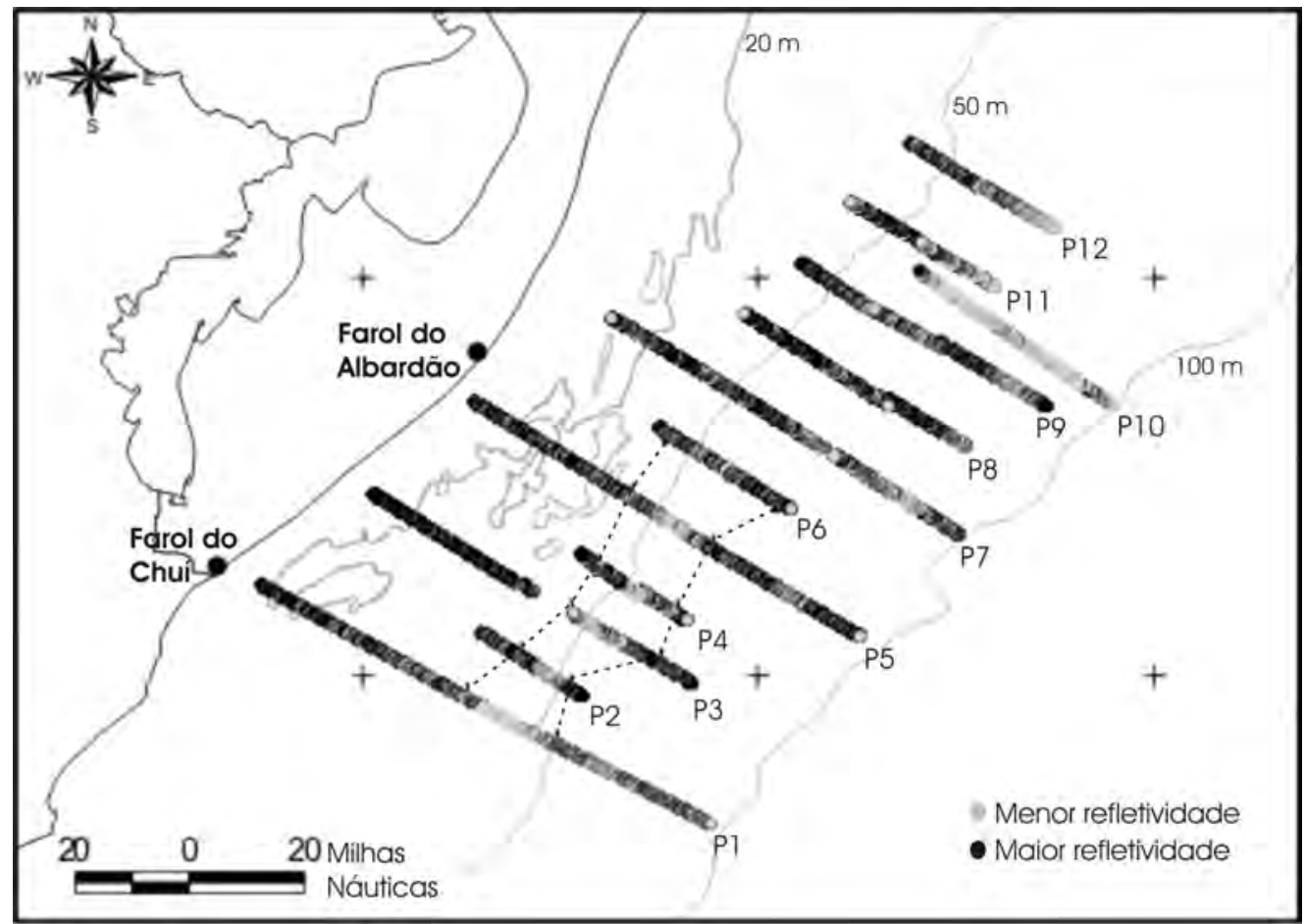

Figura 2: Prospecção hidroacústica na região do canal do Albardão, e classificação dos dados quanto à refletividade acústica do fundo. As linhas tracejadas indicam a localização do canal; as referências (P1 a P12) dizem respeito aos perfis batimétricos. 
Na figura 2 é apresentado um mapa da área de estudo, com os perfis onde foi realizada a aquisição de dados hidroacústicos, a classificação dos dados quanto à refletividade acústica do fundo, além da indicação da localização do canal nos locais onde foi possível a identificação do mesmo. As coordenadas geográficas de início e final de cada um dos perfis batimétricos são apresentadas na tabela 1 .

Tabela 1: Posições geográficas iniciais e finais dos perfis batimétricos.

\begin{tabular}{|c|c|c|}
\hline & Posição Inicial & Posição Final \\
\hline Perfil 1 & $\begin{array}{l}33^{\circ} 46,87^{\prime} \mathrm{S} \\
053^{\circ} 15,33^{\prime} \mathrm{W}\end{array}$ & $\begin{array}{l}34^{\circ 2} 23,03^{\prime} \mathrm{S} \\
052^{\circ} 07,44^{\prime} \mathrm{W}\end{array}$ \\
\hline Perfil 2 & $\begin{array}{l}33^{\circ} 53,96^{\prime}, S \\
52^{\circ} 41,98^{\prime} W\end{array}$ & $\begin{array}{l}34^{\circ} 03,611^{\prime} \mathrm{S} \\
052^{\circ} 26,82^{\prime} \mathrm{W}\end{array}$ \\
\hline Perfil 3 & $\begin{array}{l}33^{\circ} 32,66^{\prime} \mathrm{S} \\
052^{\circ} 58,92^{\prime} \mathrm{W}\end{array}$ & $\begin{array}{l}34^{\circ} 01,65^{\prime} \mathrm{S} \\
052^{\circ} 10,10^{\prime} \mathrm{W}\end{array}$ \\
\hline Perfil 4 & $\begin{array}{l}33^{\circ} 42,04^{\prime} \mathrm{S} \\
052^{\circ} 26,95^{\prime} \mathrm{W}\end{array}$ & $\begin{array}{l}33^{\circ} 52,14 \mathrm{~S} \\
052^{\circ} 10,73^{\prime} \mathrm{W}\end{array}$ \\
\hline Perfil 5 & $\begin{array}{l}33^{\circ} 19,16^{\prime} \mathrm{S} \\
02^{\circ} 43,20^{\prime} \mathrm{W}\end{array}$ & $\begin{array}{l}33^{\circ} 54,64^{\prime} \mathrm{S} \\
051^{\circ} 44,60^{\prime} \mathrm{W}\end{array}$ \\
\hline Perfil 6 & $\begin{array}{l}33^{\circ} 23,07^{\prime} \mathrm{S} \\
052^{\circ} 15,25^{\prime \prime} \mathrm{W}\end{array}$ & $\begin{array}{l}33^{\circ} 335,41^{\prime} \mathrm{S} \\
051^{\circ} 55,08^{\prime} \mathrm{W}\end{array}$ \\
\hline Perfil 7 & $\begin{array}{l}33^{\circ} 06,46^{\prime} \mathrm{S} \\
052^{\circ} 22,27^{\prime} \mathrm{W}\end{array}$ & $\begin{array}{l}33^{\circ} 39,31 \text { ' S } \\
051^{\circ} 29,42^{\prime} \mathrm{W}\end{array}$ \\
\hline Perfil 8 & $\begin{array}{l}33^{\circ} 06,00^{\prime} \mathrm{S} \\
051^{\circ} 02,13^{\prime} \mathrm{W}\end{array}$ & $\begin{array}{l}33^{\circ} 26,00^{\prime} \mathrm{S} \\
051^{\circ} 28,36^{\prime} \mathrm{W}\end{array}$ \\
\hline Perfil 9 & $\begin{array}{l}32^{\circ} 58,17^{\prime} \mathrm{S} \\
051^{\circ} 53,70^{\prime} \mathrm{W}\end{array}$ & $\begin{array}{l}33^{\circ} 19,80^{\prime} \mathrm{S} \\
051^{\circ} 16,37^{\prime} \mathrm{W}\end{array}$ \\
\hline Perfil 10 & $\begin{array}{l}33^{\circ} 11,244^{\prime} \mathrm{S} \\
51^{\circ} 18,67, \mathrm{~W}\end{array}$ & $\begin{array}{l}32^{\circ} 59,53^{\prime} \mathrm{S} \\
51^{\circ}-3558^{\prime} \mathrm{W}\end{array}$ \\
\hline Perfil 11 & $\begin{array}{l}33^{\circ} 01,97^{\prime} \mathrm{S} \\
051^{\circ} 24,13^{\prime} \mathrm{W}\end{array}$ & $\begin{array}{l}32^{\circ} 49,04^{\prime} \mathrm{S} \\
051^{\circ} 46,11^{\prime} \mathrm{W}\end{array}$ \\
\hline Perfil12 & $\begin{array}{l}32^{\circ} 39,866^{\prime} \mathrm{S} \\
051^{\circ} 37,08^{\prime} \mathrm{W}\end{array}$ & $\begin{array}{l}32^{\circ} 53,09 \text { ' S } \\
051^{\circ} 14,98 \text { ' W }\end{array}$ \\
\hline
\end{tabular}

Os perfis batimétricos são apresentados claramente, através da batimetria, o canal do ordenados de sul para norte (figuras 3 a 14), Albardão (figuras 3 a 8). Ao norte do perfil 6 o canal correspondendo às referências contidas na figura 2.

Nos perfis de 1 a 6 foi possível identificar
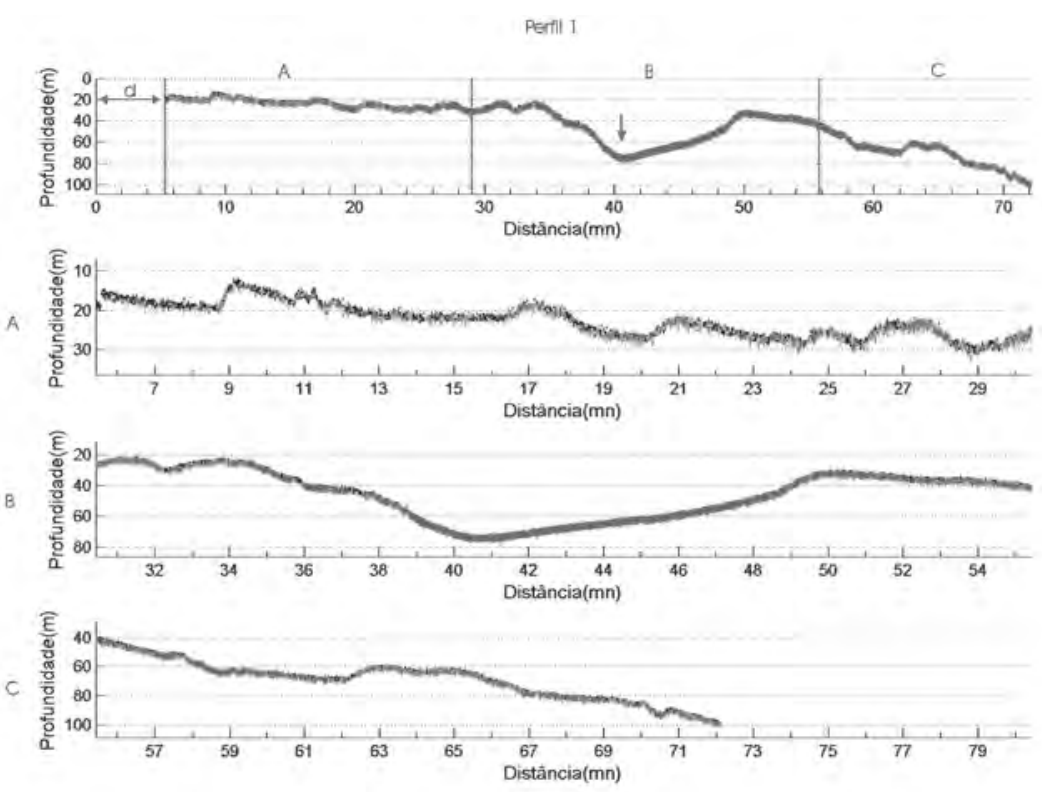

Figura 3: perfil batimétrico $1 \mathrm{com}$ dados de BSBS. Trechos com tons claros e escuros representam fundos menos e mais refletivos, respectivamente; a seta aponta o canal. $d=$ distância da costa. 
Perfil 2
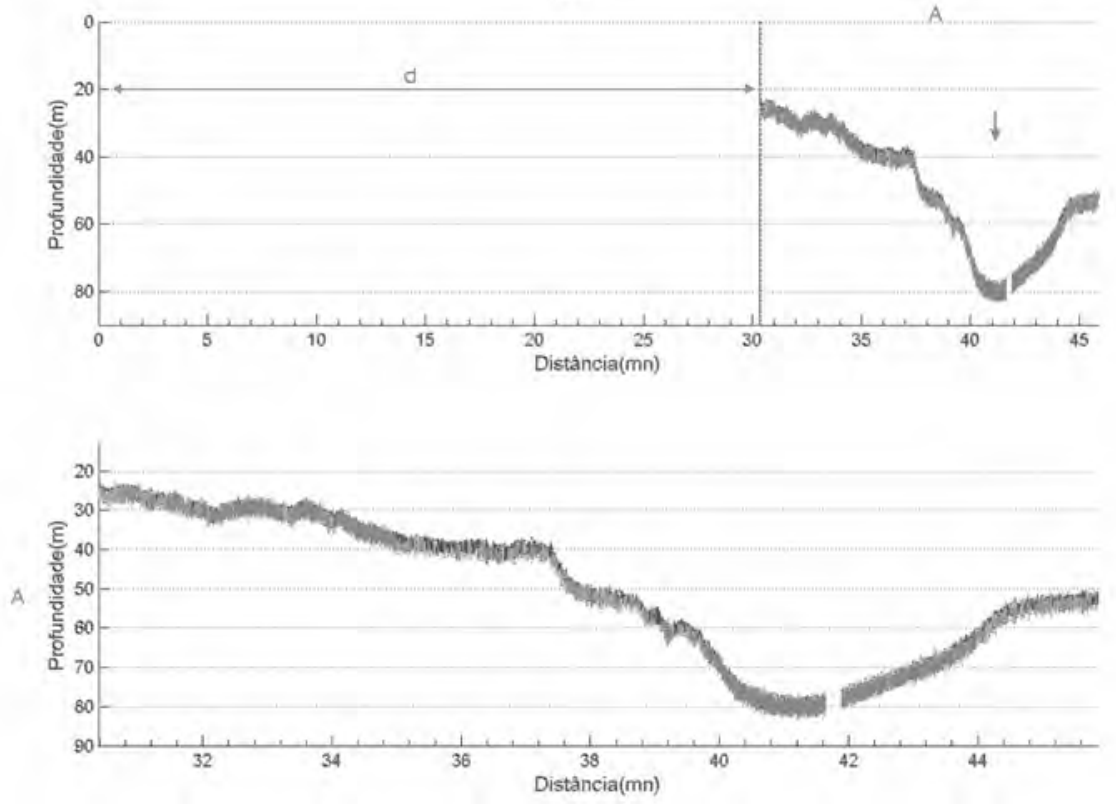

Figura 4: perfil batimétrico 2 com dados de BSBS. Trechos com tons claros e escuros representam fundos menos e mais refletivos, respectivamente; a seta aponta o canal. $d=$ distância da costa.
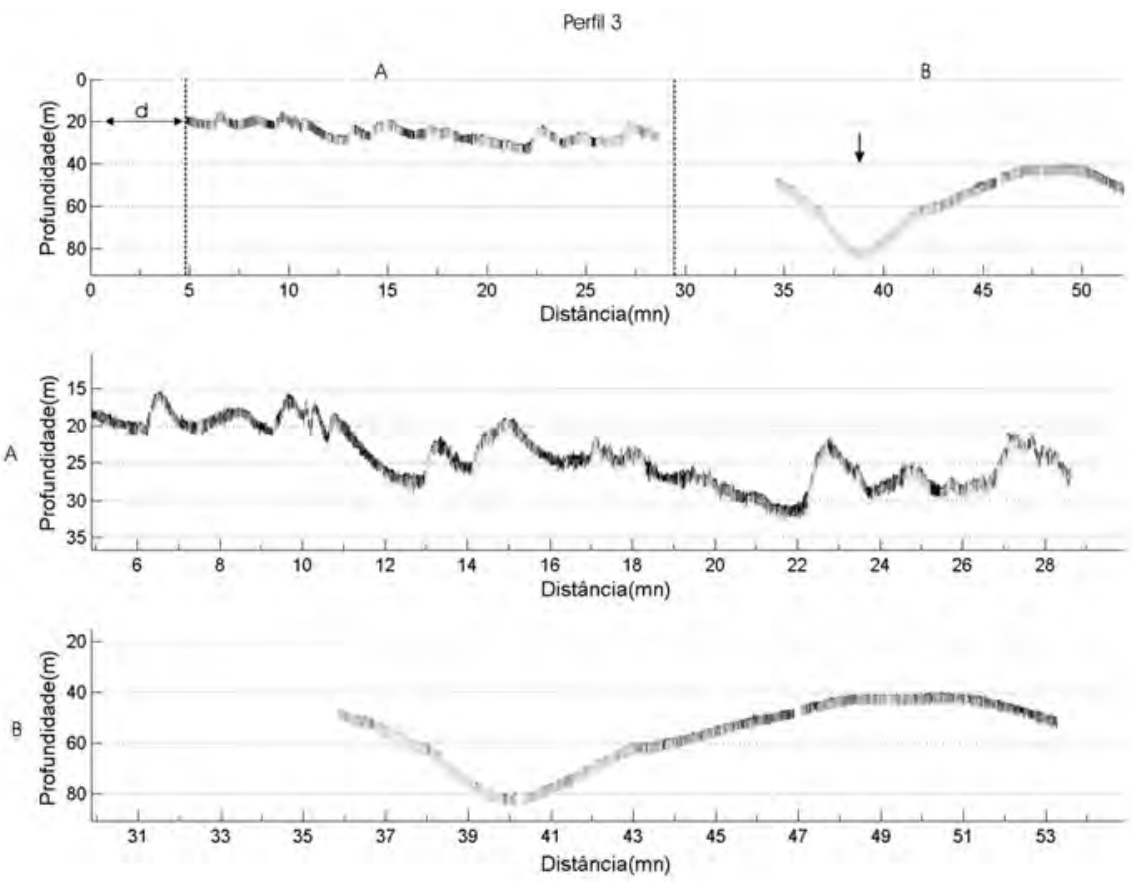

Figura 5: perfil batimétrico 3 com dados de BSBS. Trechos com tons claros e escuros representam fundos menos e mais refletivos, respectivamente; a seta aponta o canal. d=distância da costa. 

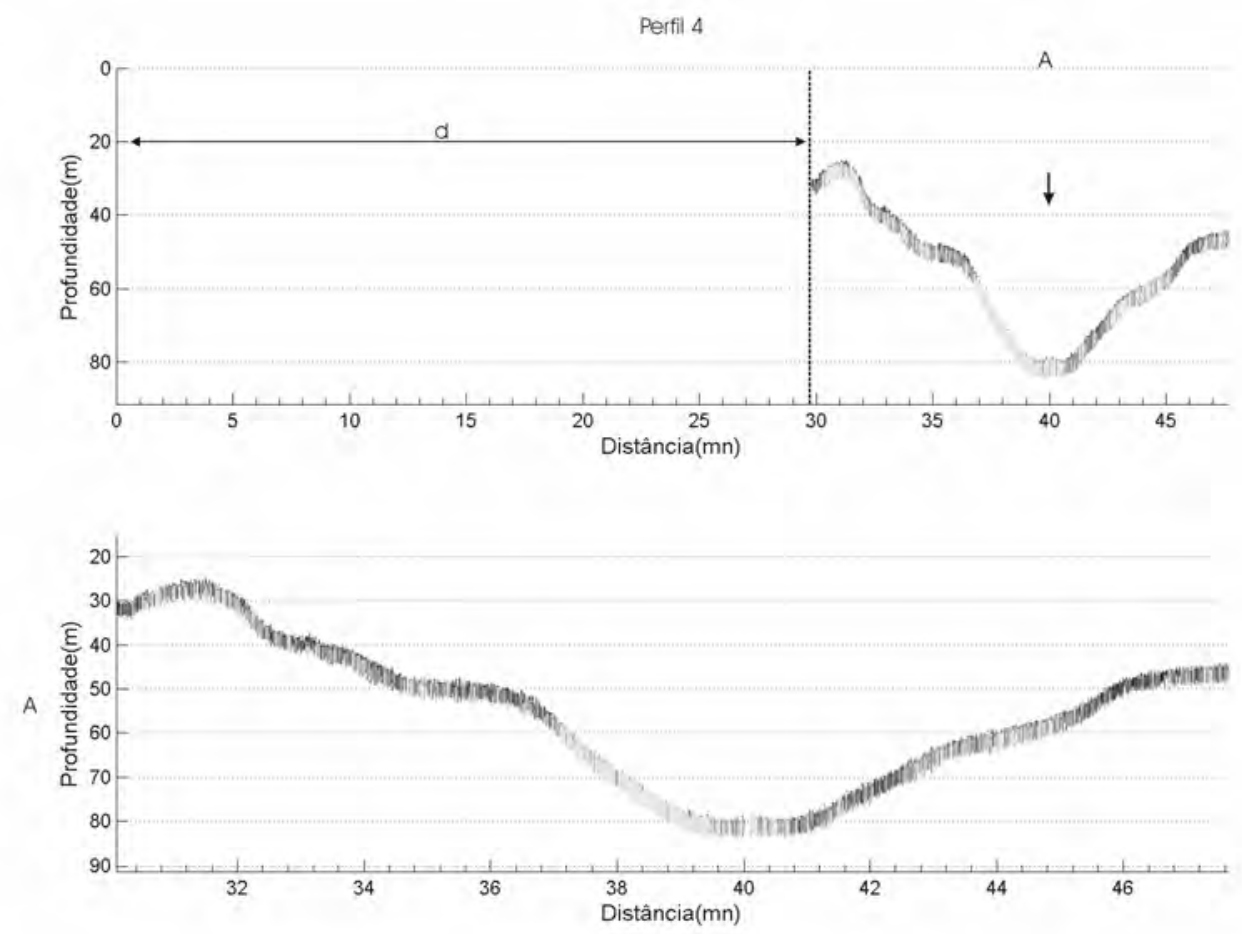

Figura 6: perfil batimétrico 4 com dados de BSBS. Trechos com tons claros e escuros representam fundos menos e mais refletivos, respectivamente; a seta aponta o canal. $d=$ distância da costa.

Perfil 5
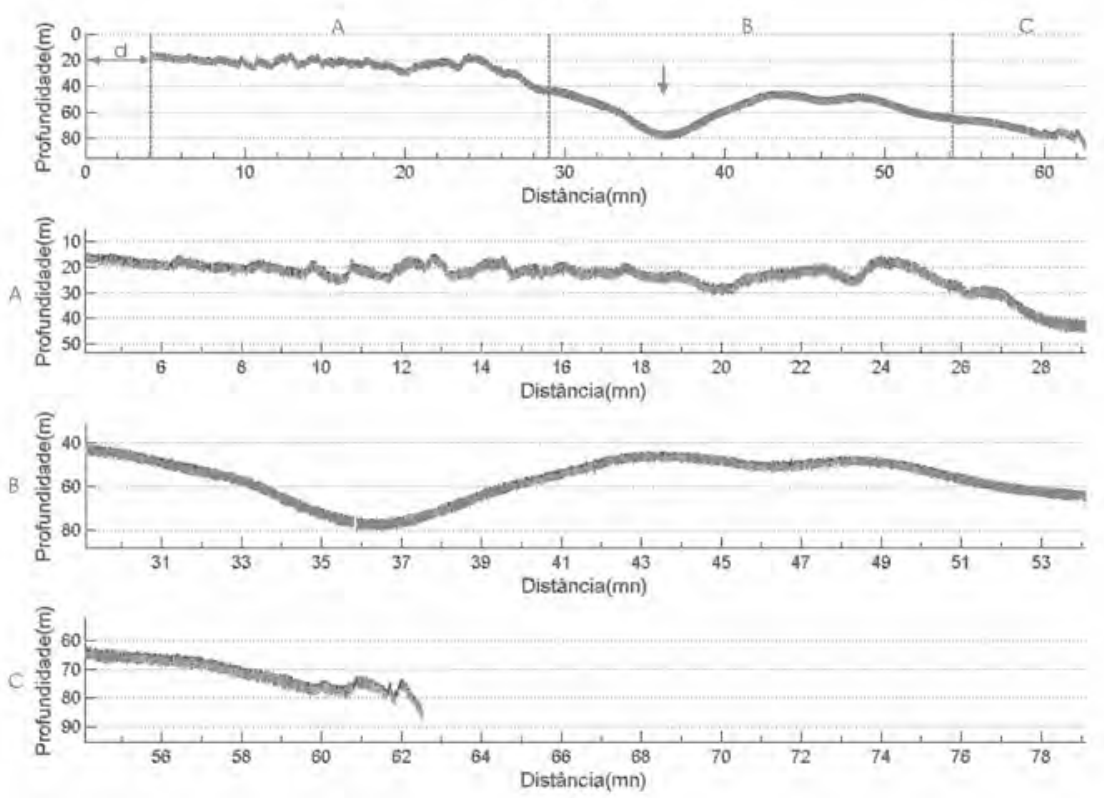

Figura 7: perfil batimétrico 5 com dados de BSBS. Trechos com tons claros e escuros representam fundos menos e mais refletivos, respectivamente; a seta aponta o canal. d=distância da costa. 
Perfil 6
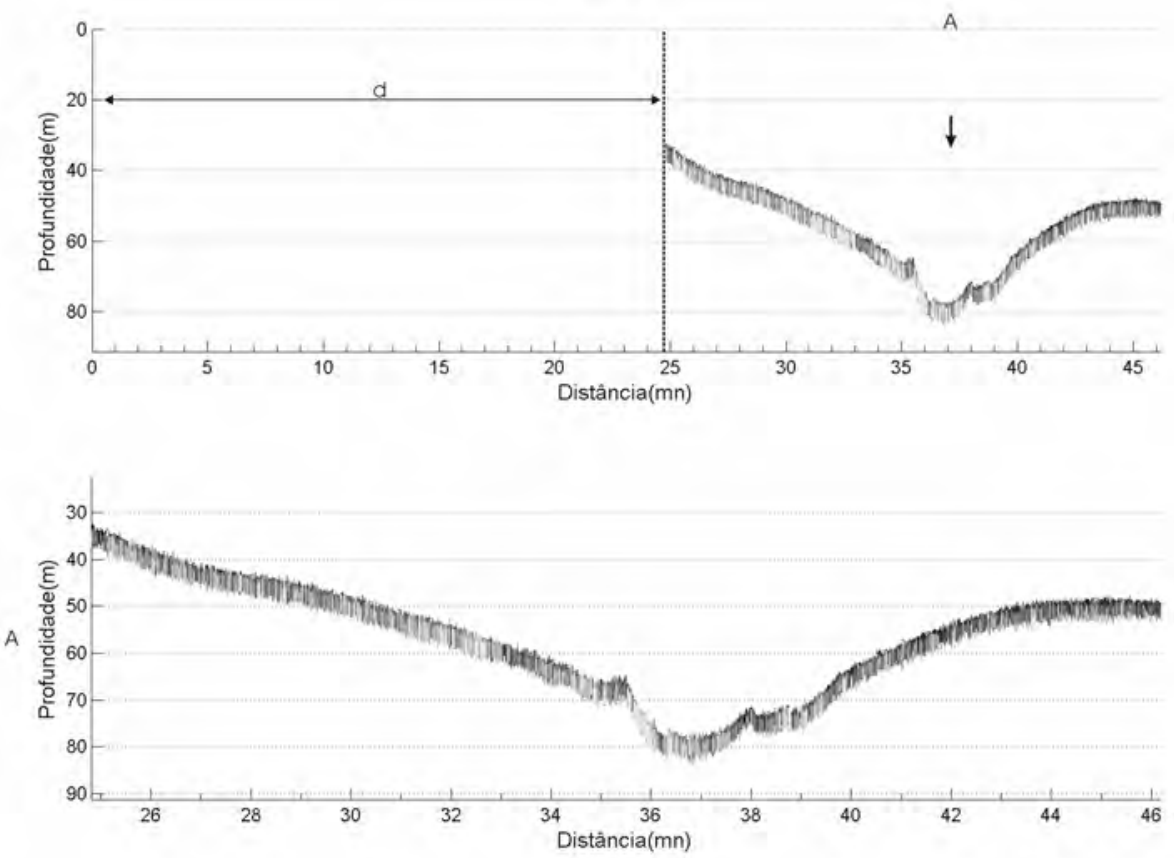

Figura 8: perfil batimétrico 6 com dados de BSBS. Trechos com tons claros e escuros representam fundos menos e mais refletivos, respectivamente; a seta aponta o canal. d=distância da costa.

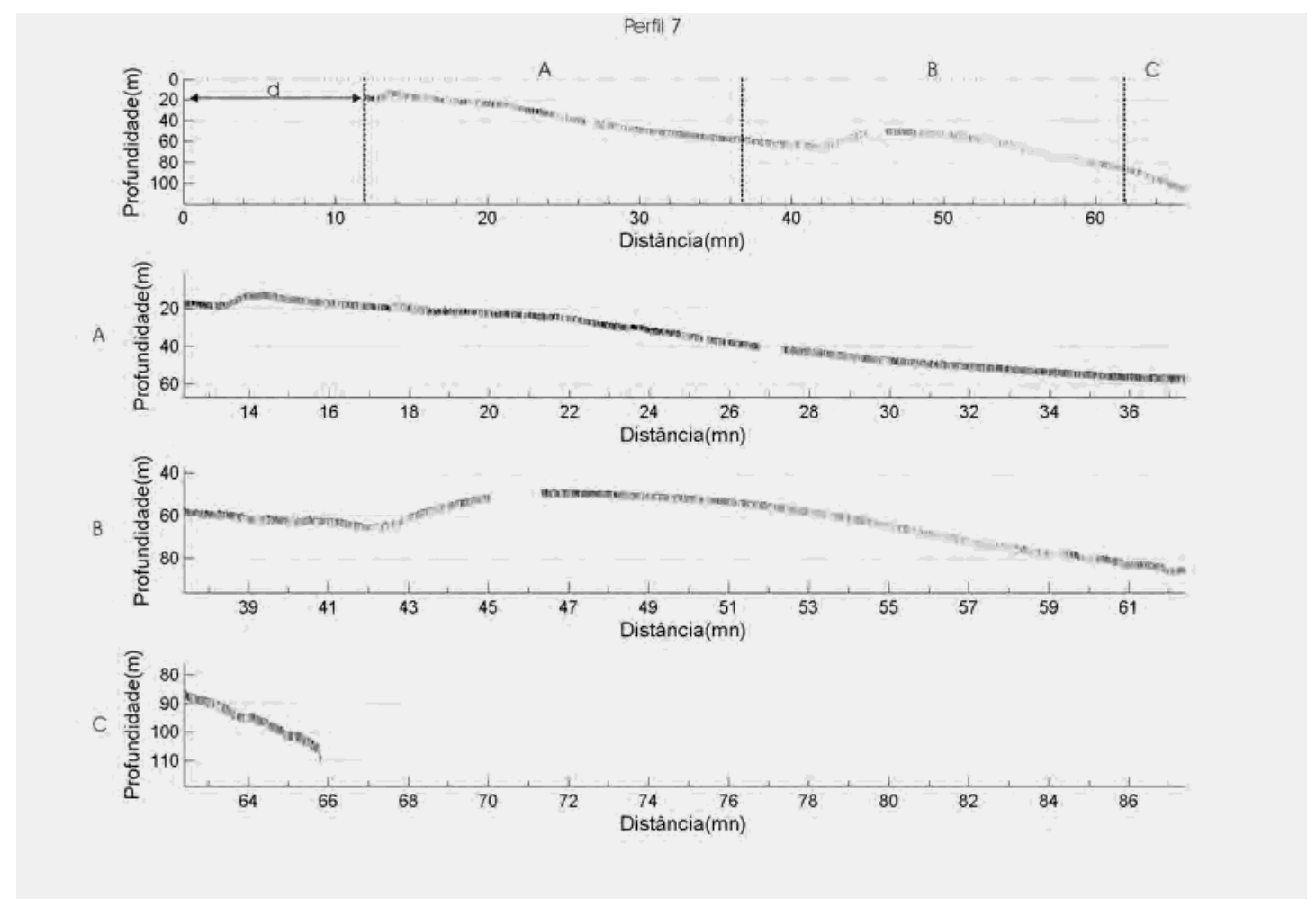

Figura 9: perfil batimétrico 7 com dados de BSBS. Trechos com tons claros e escuros representam fundos menos e mais refletivos, respectivamente. $d=$ distância da costa. 

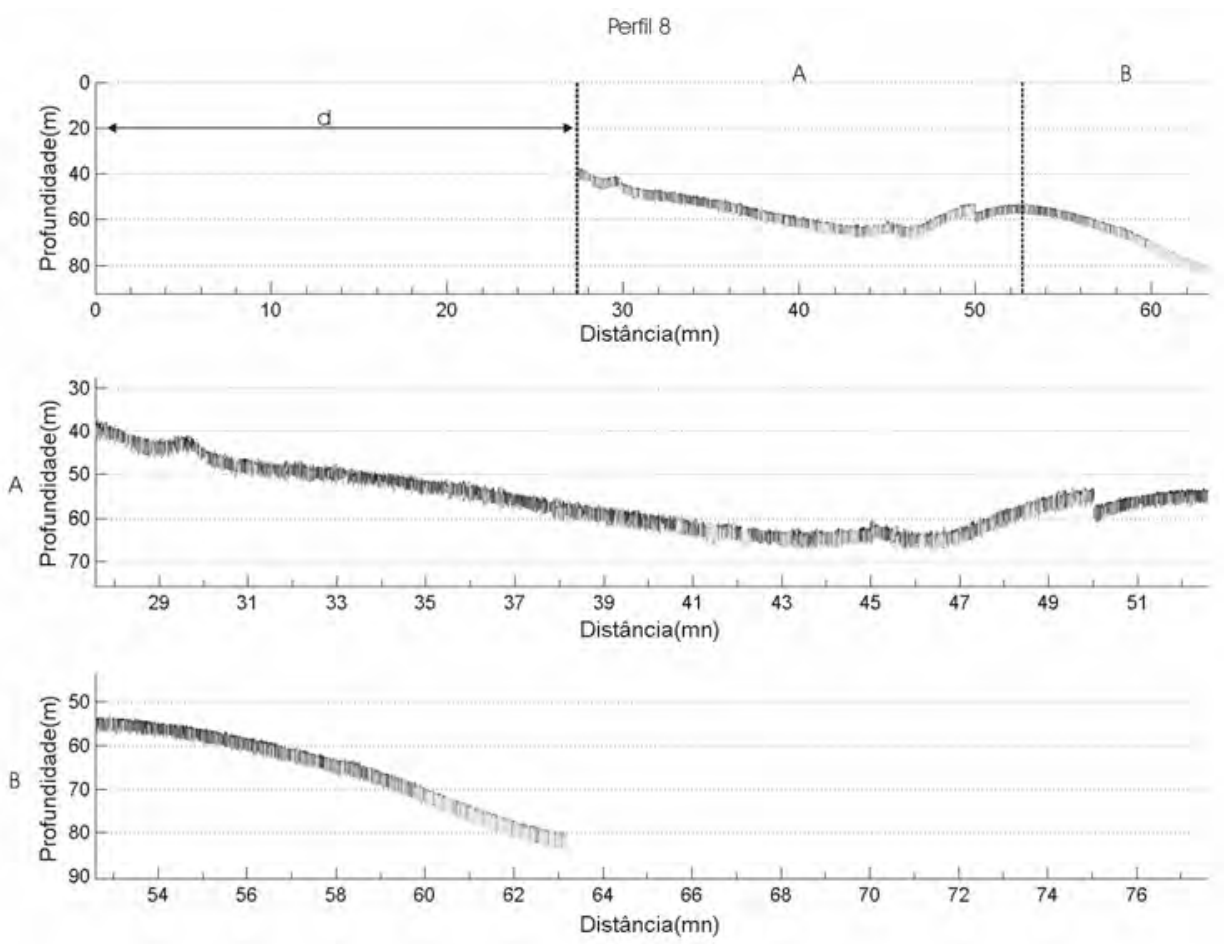

Figura 10: perfil batimétrico 8 com dados de BSBS. Trechos com tons claros e escuros representam fundos menos e mais refletivos, respectivamente. $d=$ distância da costa.
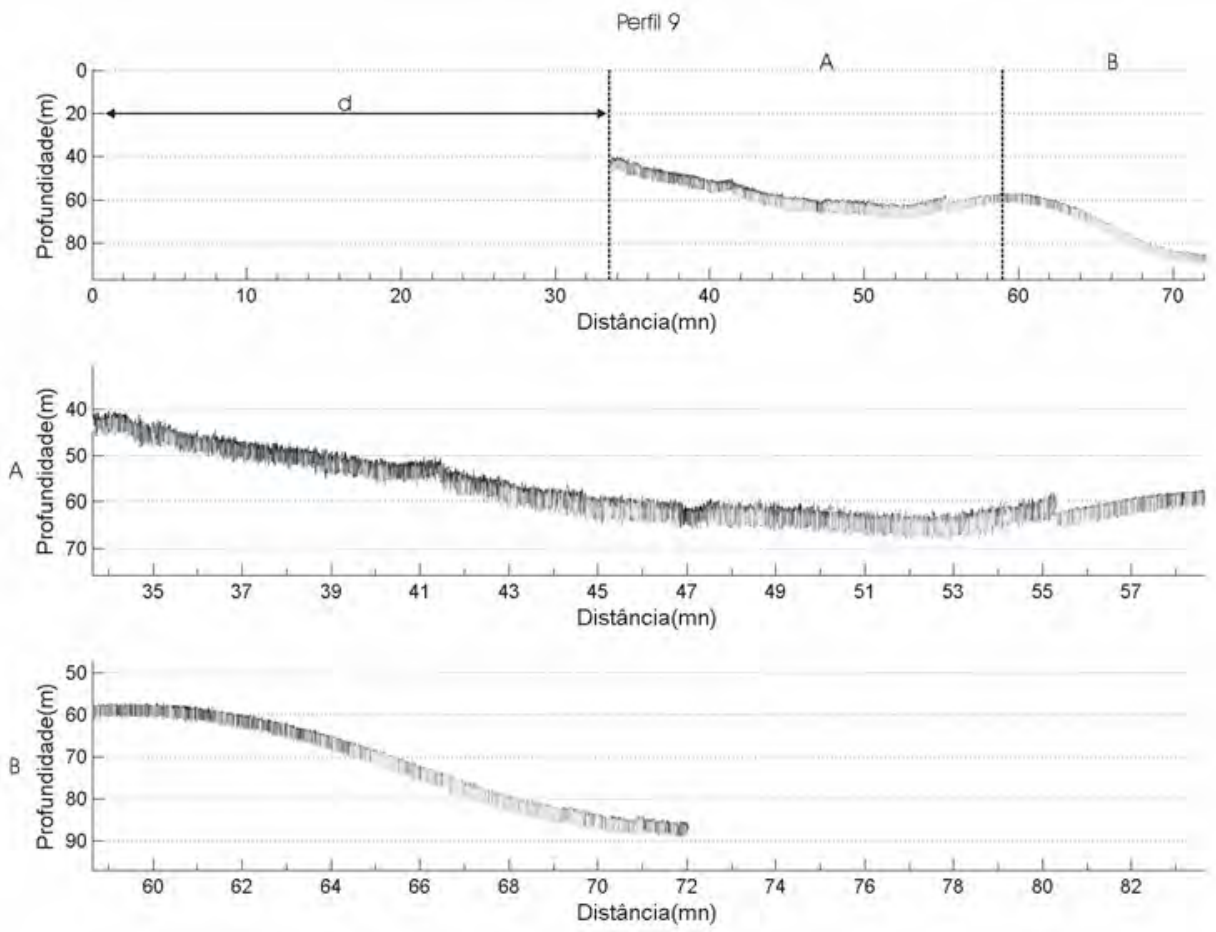

Figura 11: perfil batimétrico 9 com dados de BSBS. Trechos com tons claros e escuros representam fundos menos e mais refletivos, respectivamente. $d=$ distância da costa. 
Perfil 10
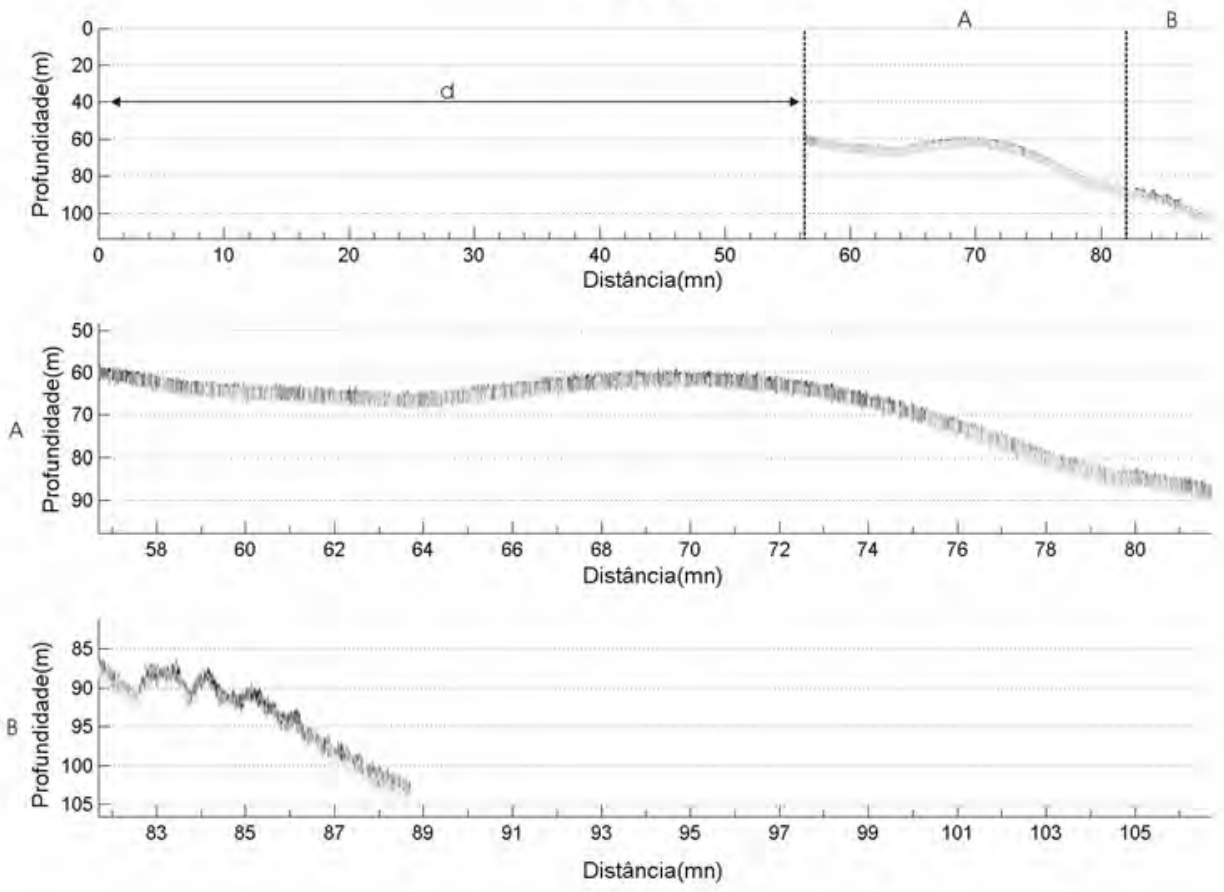

Figura 12: perfil batimétrico $10 \mathrm{com}$ dados de BSBS. Trechos com tons claros e escuros representam fundos menos e mais refletivos, respectivamente. d=distância da costa.

Perfil 11
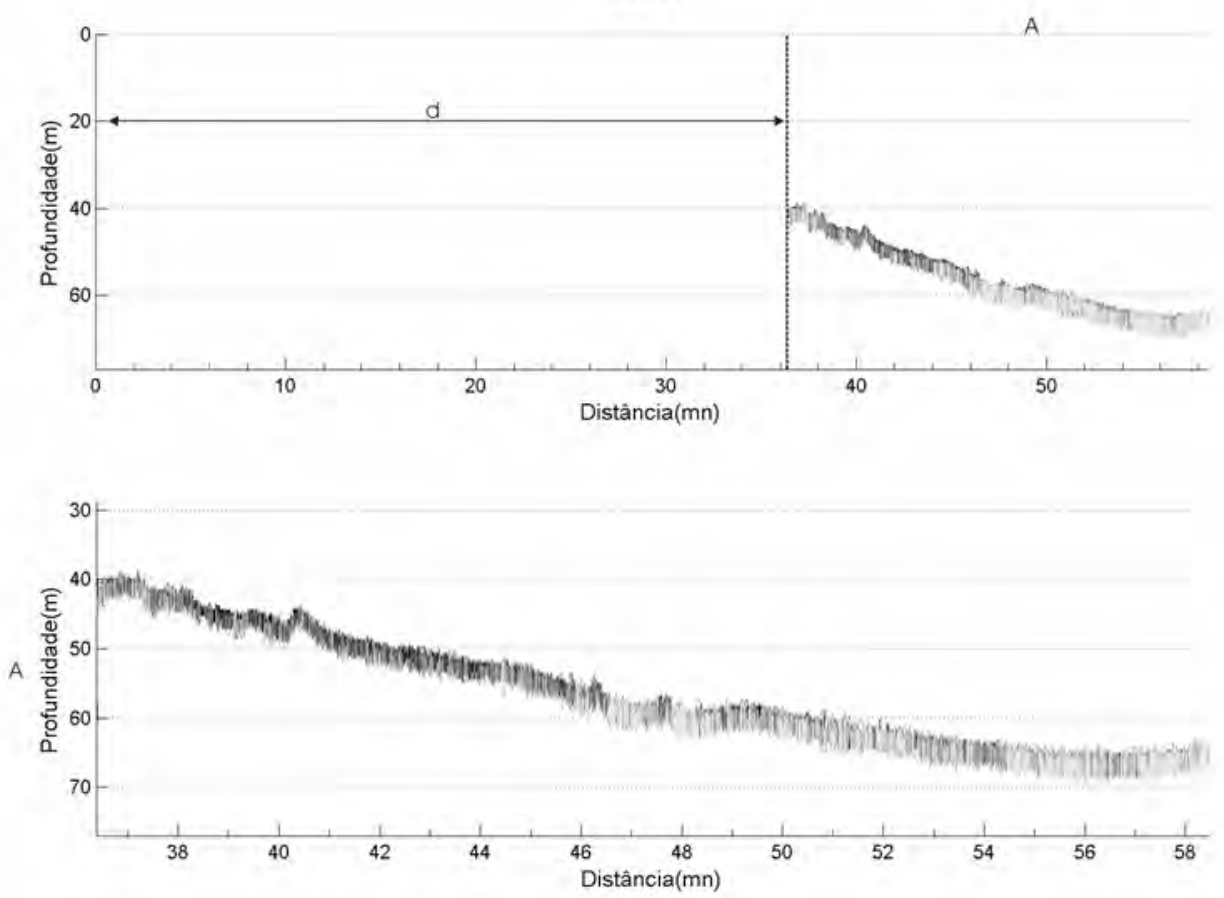

Figura 13: perfil batimétrico 11 com dados de BSBS. Trechos com tons claros e escuros representam fundos menos e mais refletivos, respectivamente. d=distância da costa. 
Perfil 12
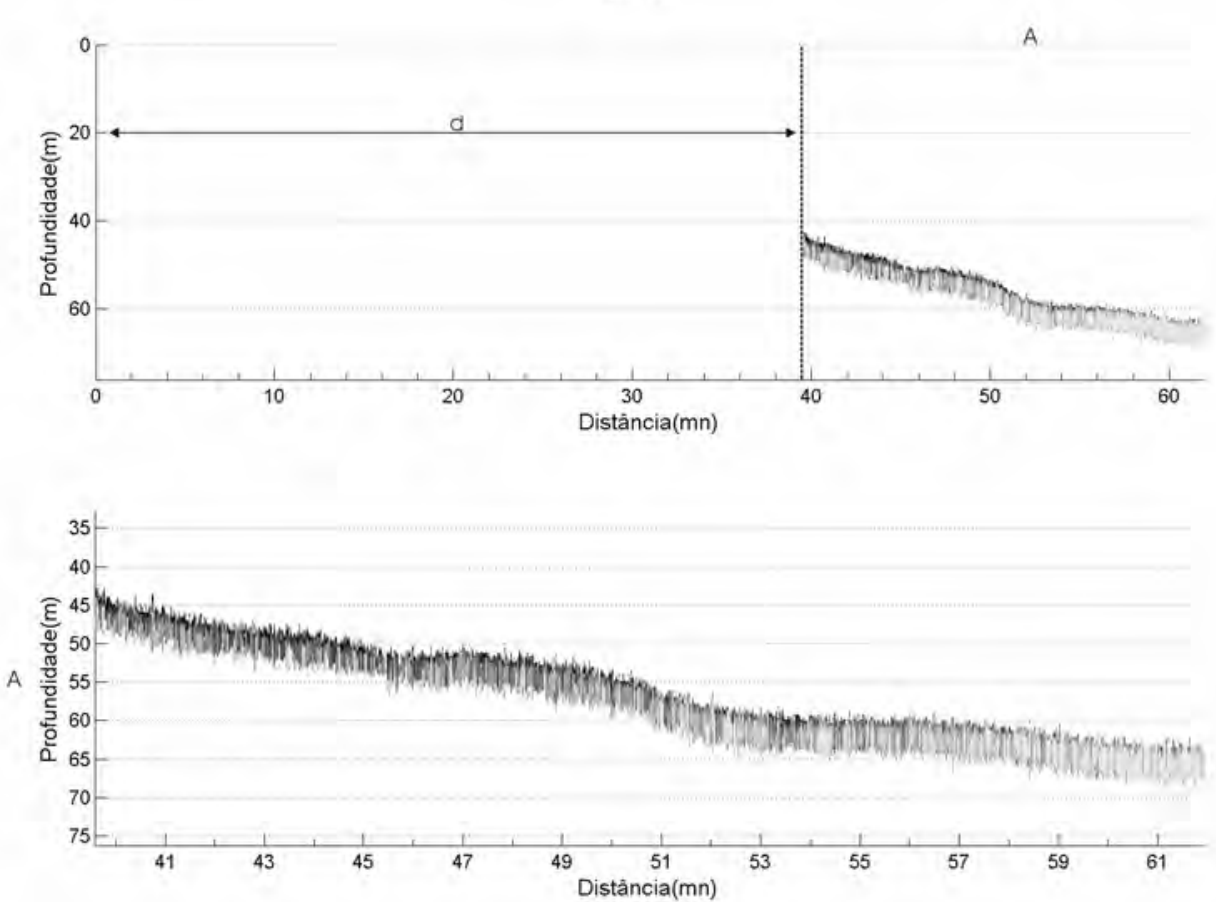

Figura 14: perfil batimétrico 12 com dados de BSBS. Trechos com tons claros e escuros representam fundos menos e mais refletivos, respectivamente. d=distância da costa.

A partir desta delimitação calculou-se que o canal apresenta um comprimento de cerca de $47 \mathrm{mn}$ (87 km), ocupando uma área aproximada de $670 \mathrm{mn} 2$

Tabela 2: Posições geográficas relativas às bordas do canal do Albardão.

\begin{tabular}{ccc}
\hline Perfil & Latitude (S) & Longitude (W) \\
\hline \multirow{2}{*}{1} & $34^{\circ} 03,6^{\prime}$ & $052^{\circ} 43,8^{\prime}$ \\
& $34^{\circ} 10,8^{\prime}$ & $052^{\circ} 30,6^{\prime}$ \\
\hline \multirow{2}{*}{3} & $33^{\circ} 57,6^{\prime}$ & $052^{\circ} 36,0^{\prime}$ \\
& $34^{\circ} 02,4^{\prime}$ & $052^{\circ} 28,2^{\prime}$ \\
\hline 3 & $33^{\circ} 51,0^{\prime}$ & $052^{\circ} 28,2^{\prime}$ \\
\hline 4 & $33^{\circ} 58,8^{\prime}$ & $052^{\circ} 14,4^{\prime}$ \\
\hline \multirow{2}{*}{5} & $33^{\circ} 43,8^{\prime}$ & $052^{\circ} 24,0^{\prime}$ \\
& $33^{\circ} 51,0^{\prime}$ & $052^{\circ} 12,0^{\prime}$ \\
\hline 6 & $33^{\circ} 33,6^{\prime}$ & $052^{\circ} 19,2^{\prime}$ \\
& $33^{\circ} 41,4^{\prime}$ & $052^{\circ} 07,2^{\prime}$ \\
\hline
\end{tabular}

Os resultados dos testes estatísticos de comparação de médias indicam diferenças extremamente significativas $(p<0,001)$ entre os valores
(2.293,4 Km2). As posições geográficas relativas às bordas do canal são apresentadas na tabela 2 . 
Tabela 3: Média, desvio padrão (DP) e número de leituras (n) de BSBS, dentro e fora do canal.

\begin{tabular}{ccccc} 
& Local & BSBS Médio $(\mathrm{dB})$ & $\mathrm{DP}$ & $\mathrm{n}$ \\
\hline Perfil 01 & Dentro & $-16,0$ & 4,30 & 1090 \\
& Fora & $-10,6$ & 4,81 & 1238 \\
\hline Perfil 02 & Dentro & $-15,9$ & 4,37 & 814 \\
& Fora & $-8,3$ & 4,64 & 686 \\
\hline Perfil 03 & Dentro & $-16,9$ & 3,73 & 609 \\
& Fora & $-11,7$ & 4,29 & 597 \\
\hline Perfil 04 & Dentro & $-16,8$ & 3,80 & 844 \\
& Fora & $-9,6$ & 4,55 & 798 \\
\hline Perfil 05 & Dentro & $-17,7$ & 3,64 & 544 \\
& Fora & $-11,0$ & 4,21 & 585 \\
\hline Perfil 06 & Dentro & $-13,7$ & 4,46 & 839 \\
& Fora & $-8,9$ & 4,53 & 775 \\
\hline
\end{tabular}

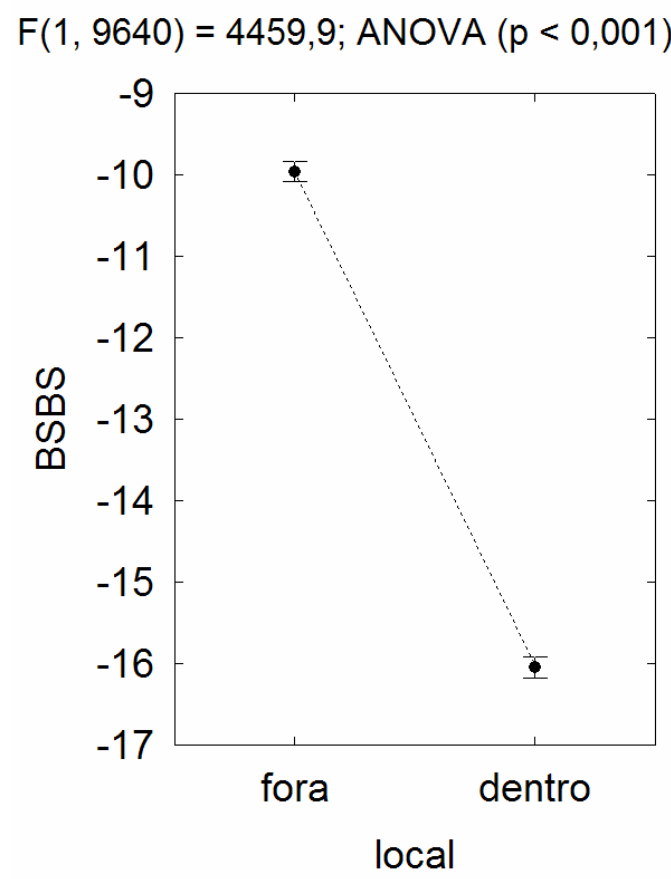

Figura 15: Comparação entre os valores médios de BSBS (dB) considerando o total dos dados agrupados. As barras de erro, no eixo da ordenadas, representam o intervalo de confiança $(\alpha=0,05)$. 


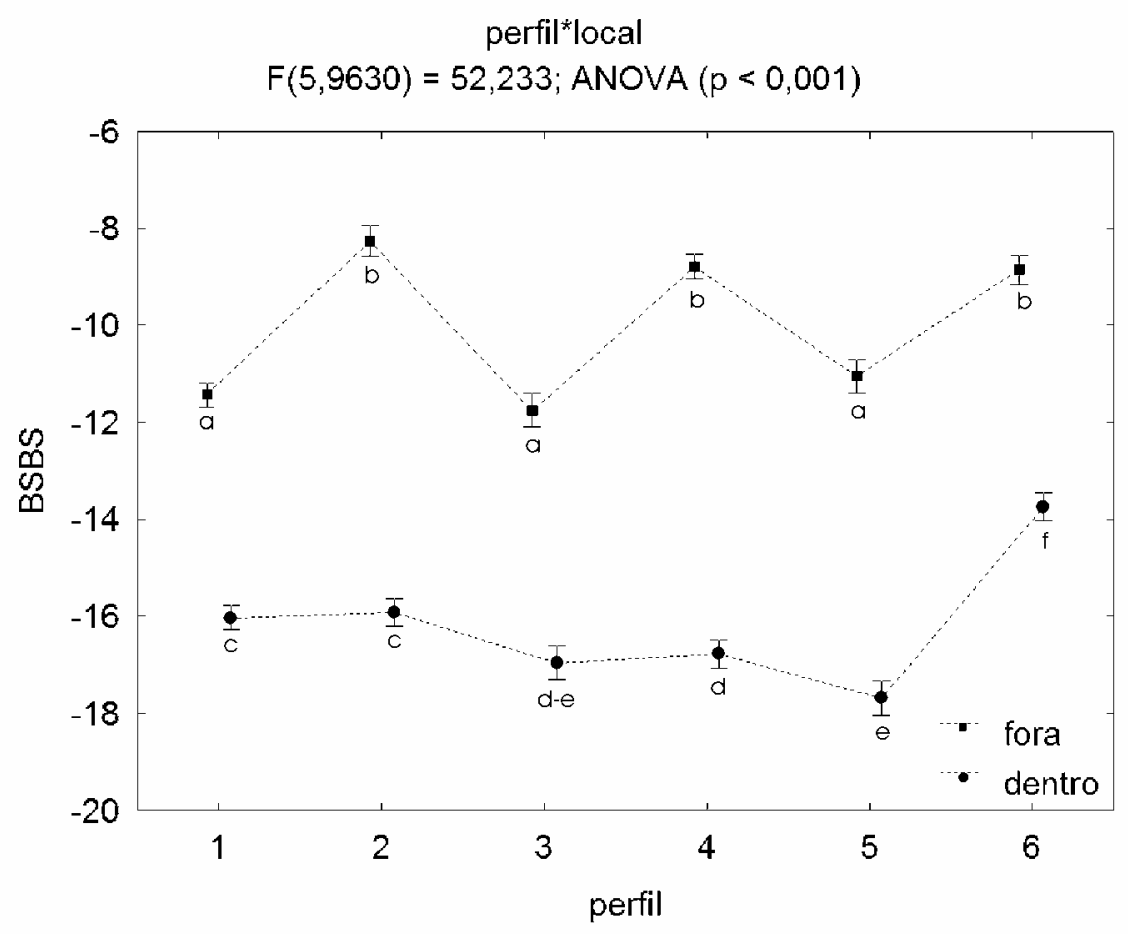

Figura 16: Comparação entre os valores médios de BSBS (dB) entre perfis e os diferentes locais (dentro e fora do canal). As barras de erro, no eixo das ordenadas, representam o intervalo de confiança $(\alpha=0,05)$. Letras diferentes indicam haver diferença significativa $(p<0,05)$, segundo o teste de Tuckey-HSD.

A análise das distribuições de freqüência relativa dos valores de BSBS, para os locais dentro e fora (figuras 17 a 22), confirma a tendência de deslocamento das modas em direção a maiores valores (maior dureza de fundo) para os dados coletados imediatamente fora do canal.

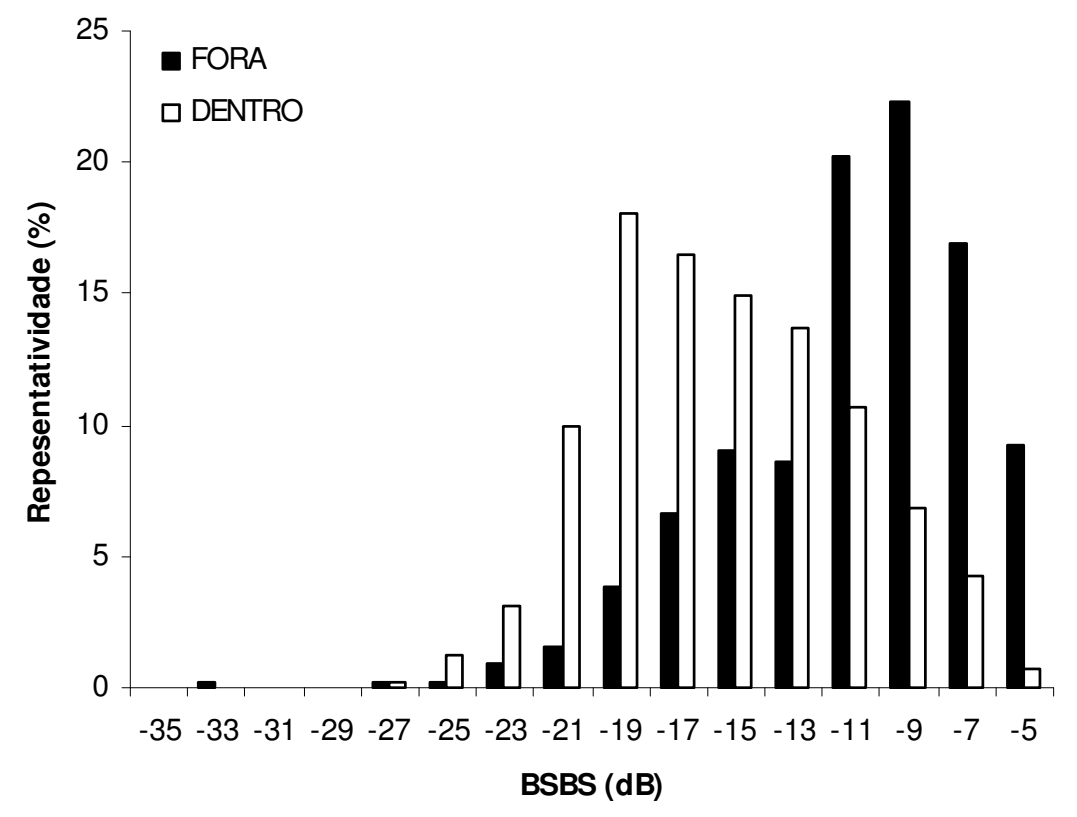

Figura 17: Distribuição de freqüência relativa das leituras de dureza de fundo para o perfil 1. 


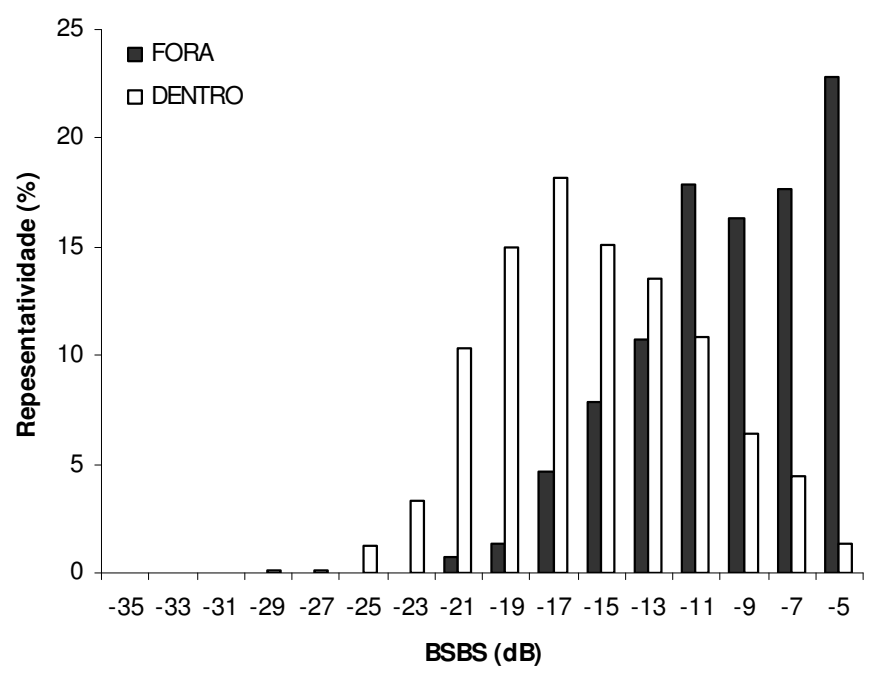

Figura 18: Distribuição de freqüência relativa das leituras de dureza de fundo para o perfil 2.

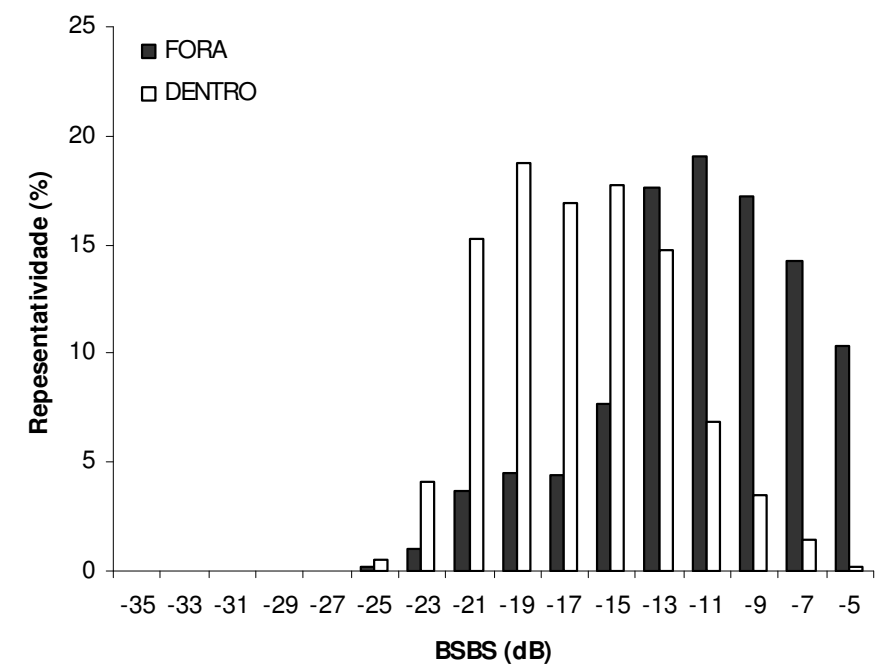

Figura 19: Distribuição de freqüência relativa das leituras de dureza de fundo para o perfil 3.

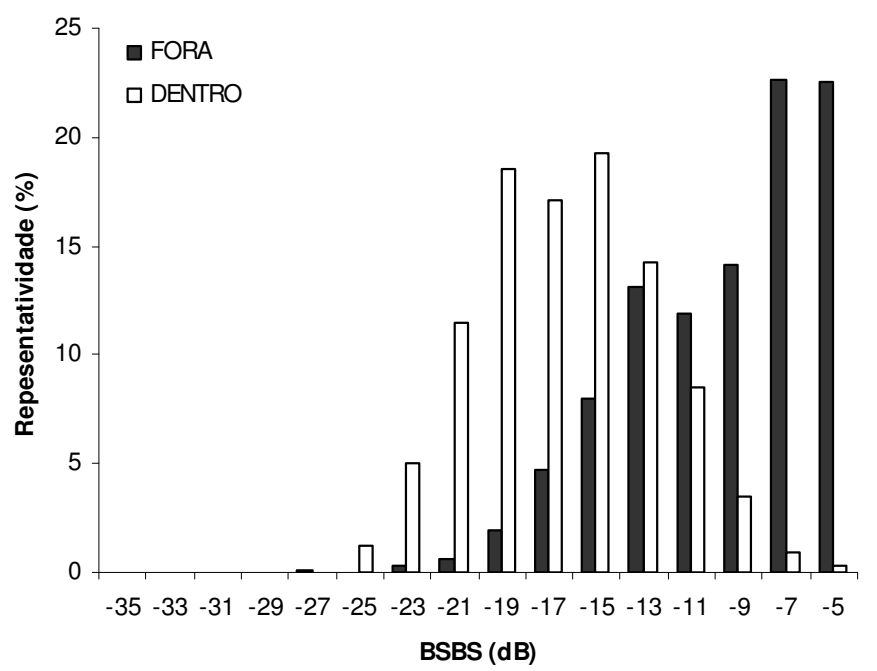

Figura 20: Distribuição de freqüência relativa das leituras de dureza de fundo para o perfil 4. 


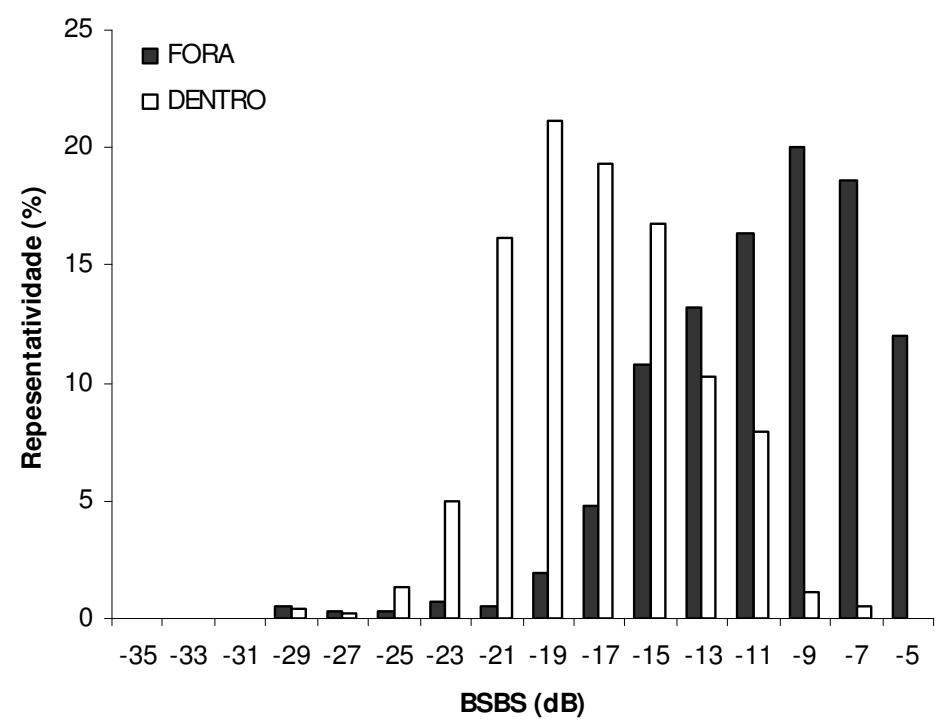

Figura 21: Distribuição de freqüência relativa das leituras de dureza de fundo para o perfil 5.

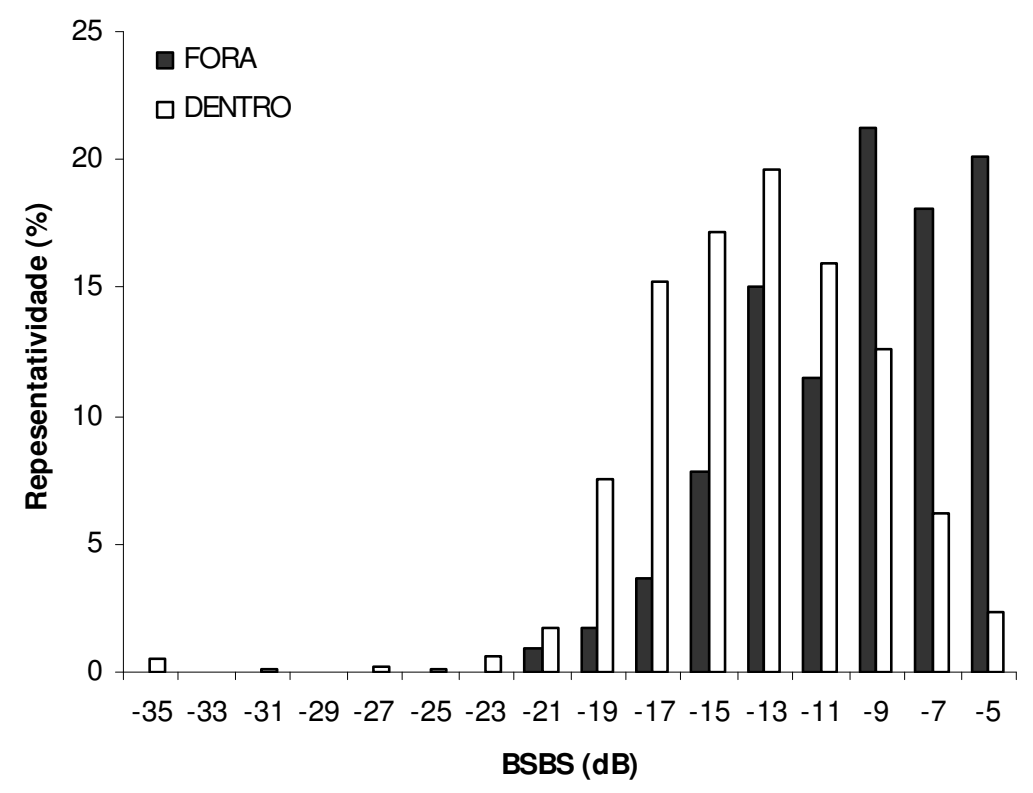

Figura 22: Distribuição de freqüência relativa das leituras de dureza de fundo para o perfil 6.

Em relação à batimetria, o canal do Albardão apresenta-se como uma feição contínua na área mapeada. A partir da matriz de dados batimétricos foi realizada a interpolação e gerada uma superfície 3D de parte do canal do Albardão (figura 23). Sobre a malha interpolada foi inserida o deslocamento realizado pela embarcação, para avaliação do posicionamento dos dados batimétricos em relação à superfície (figura 24). 


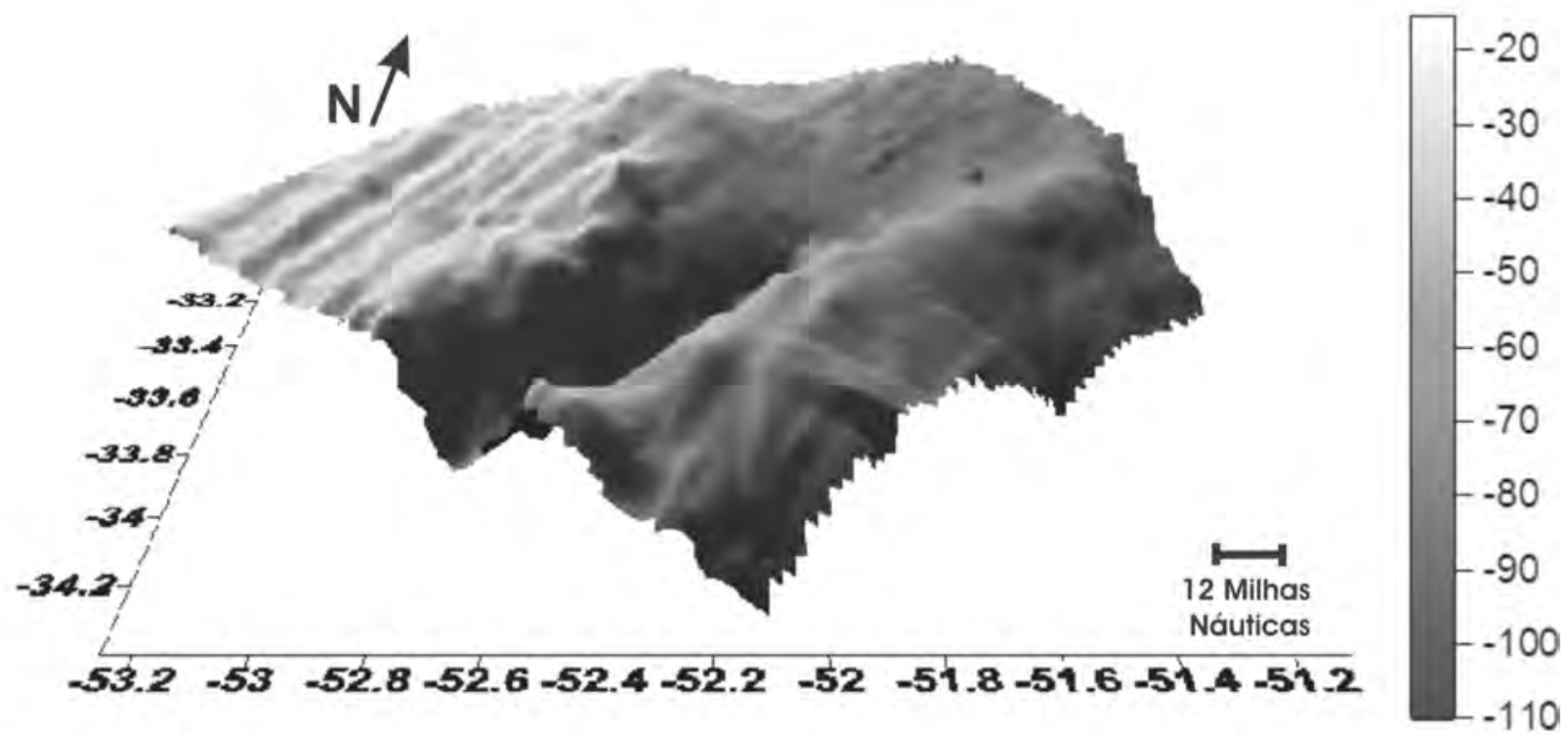

Figura 23: Superfície 3D, representando a batimetria de parte do canal do Albardão, de onde se dispunha de dados acústicos.

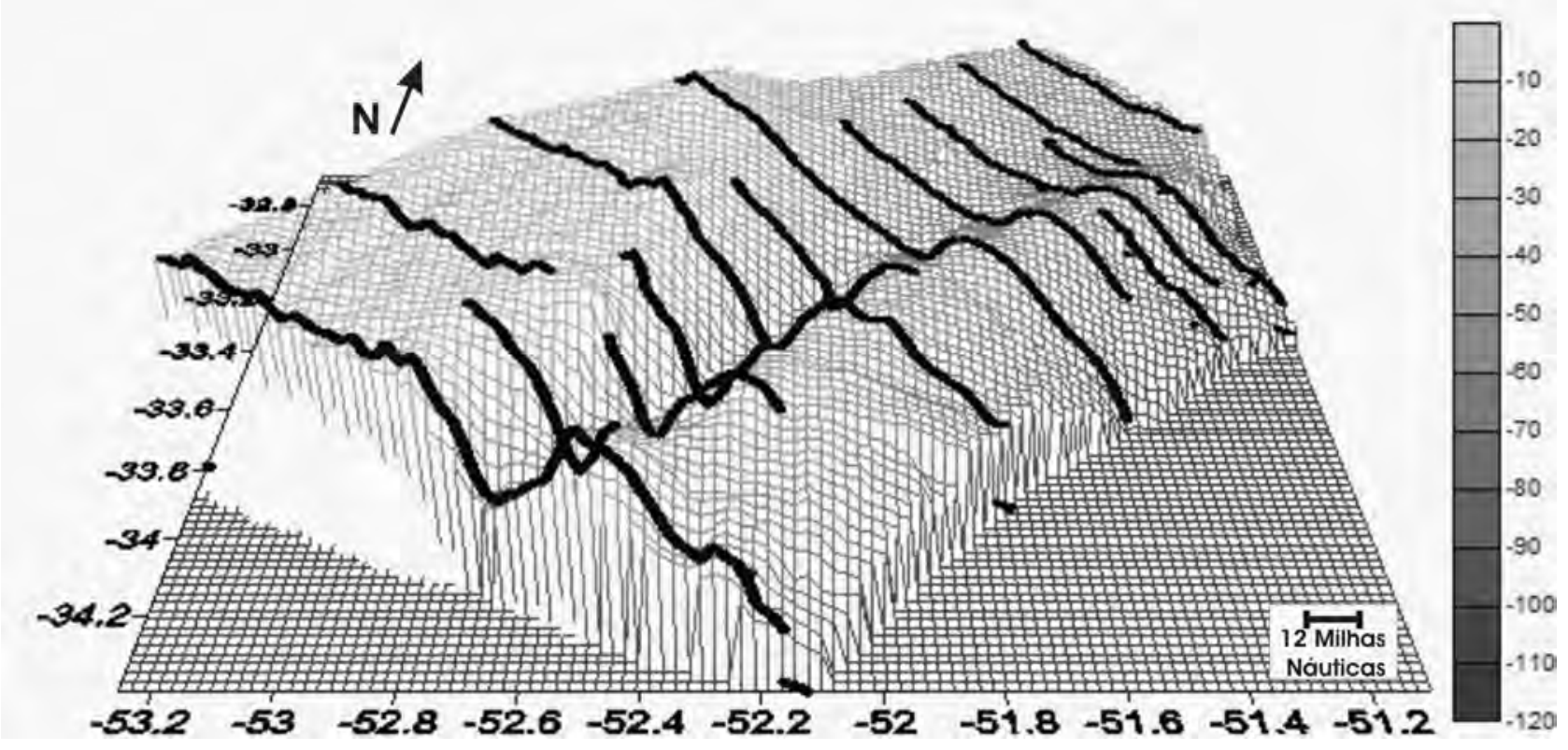

Figura 24: Malha interpolada. As linhas pretas representam o percurso realizado pela embarcação, quando da coleta dos dados batimétricos.

\section{DISCUSSÃO E CONSIDERAÇÕES FINAIS}

Os resultados deste estudo indicam ser possível a identificação do canal do Albardão, a partir de dados batimétricos, na plataforma continental da região compreendida entre a divisa marítima UruguaiBrasil e a latitude do Farol do Albardão. O parâmetro acústico BSBS corroborou a presença do canal, uma vez que diferenças extremamente significativas foram observadas na dureza acústica do fundo, indicando fundos menos consolidados nas áreas mais profundas dos trechos do canal, relativamente aos setores externos adjacentes.

Ao sul da divisa marítima, em águas territoriais Uruguaias, apesar de não ter havido coleta de dados batimétricos neste estudo, a presença do canal é reportada por Framiñan (2005). Ao norte do Farol do 
Albardão o canal torna-se pouco evidente, sendo difícil a sua distinção a partir de dados batimétricos.

A presença desta feição geomorfológica sobre a plataforma da região sul do Rio Grande do Sul condiciona o fluxo de diferentes massas de água, o que acaba por refletir na distribuição de organismos.

Evidências de que 0 fluxo de Água Subantártica de Plataforma (ASAP) se efetua principalmente através do canal do Albardão foram apontadas por Capitoli (2002). Segundo o autor, essa intrusão de ASAP no inverno é um fator determinante na distribuição de organismos bentônicos.

Aseff (2006) encontrou águas com características de ASAP sendo conduzidas para o norte, pelo canal, no outono de 1991, enquanto, na mesma estação do ano, em 2002 houve uma intrusão de Água Subtropical de Plataforma (ASTP) sendo conduzida para o sul. Na superfície, em ambas as ocasiões, a região esteve dominada pela Água Continental (AC).

Além da intrusão de diferentes massas de água, sabe-se que o tipo de substrato tem grande influência na distribuição e abundância da fauna de macroinvertebrados bentônicos (Gray 1981), os quais são presas que determinam a presença de teleósteos demersais na região.

Quanto à sua batimetria, o canal do Albardão aparece na carta náutica $\mathrm{N}^{\circ} 90$ da $\mathrm{DHN}$ como uma feição descontínua. De acordo com dados coletados no cruzeiro SAFARI tal fato não corresponde à realidade, sendo que as profundidades locais apresentadas na carta náutica são até $40 \mathrm{~m}$ menores do que as observadas nas posições correspondentes (Möller com. pes.). Estas informações, conjuntamente com as do presente estudo, indicam a continuidade batimétrica que define 0 canal, onde a carta náutica $\mathrm{N} \times 90$ apresenta uma descontinuidade.

$\mathrm{Na}$ Figura 25 as posições geográficas correspondentes às bordas do canal (Tabela 2) foram inseridas sobre o trecho da carta náutica № 90 referente à região do canal do Albardão. Nela destacam-se os pontos (A) e (B), os quais correspondem aos locais de maior profundidade do canal sobre os perfis 2 e 3 , respectivamente. Em ambos os pontos as profundidades indicadas na carta náutica são em torno de $50 \mathrm{~m}$, enquanto que as profundidades observadas em campo são de 77 e 80 $m$, respectivamente para os pontos $(A)$ e $(B)$.

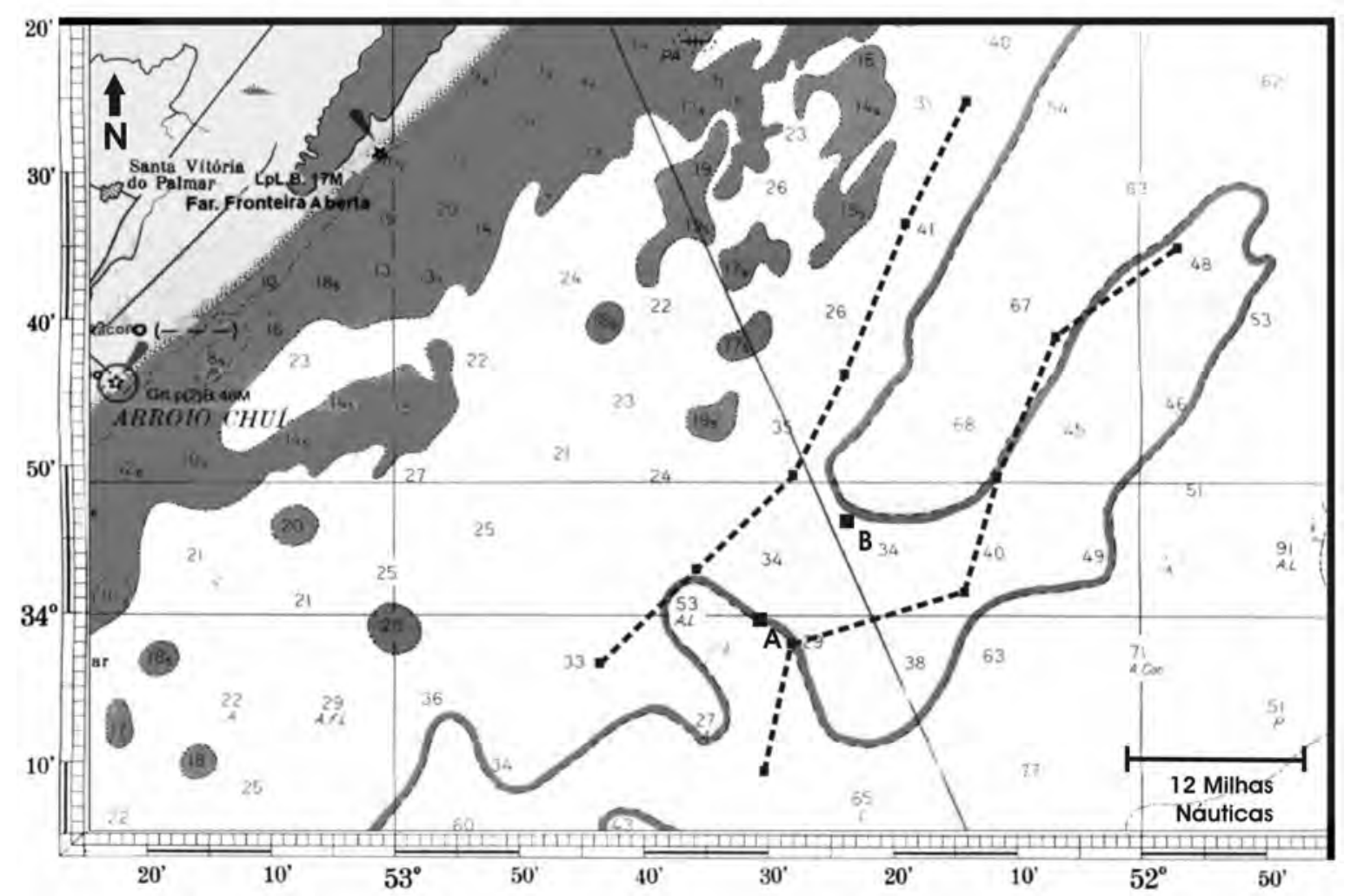

Figura 25: Trecho modificado da carta náutica № 90 da DHN. As linhas tracejadas indicam a localização do canal, e os pontos "A" e "B" as posições de maior profundidade do canal sobre os perfis 2 e 3 , respectivamente. 

As posições das bordas do canal foram também inseridas sobre um mapa de distribuição dos sedimentos granulometricamente classificados (modificado de Figueiredo \& Madureira 2004), apresentando um bom ajuste com a distribuição dos sedimentos finos (lama e lama arenosa), especialmente na porção interna sul do canal, onde a borda do canal acompanha exatamente a transição entre areia e lama (Figura 26). O mapa sedimentológico reforça a idéia da continuidade batimétrica, uma vez que a faixa de lama não apresenta qualquer interrupção no local em questão.

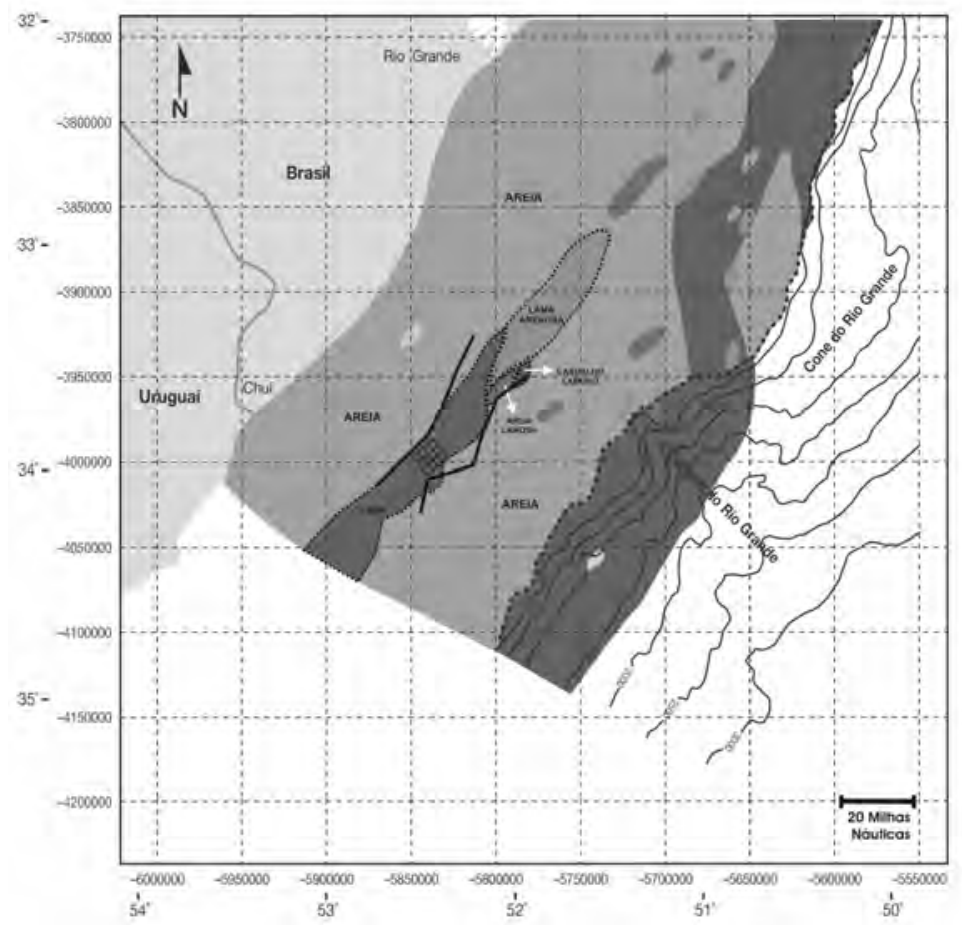

Figura 26: Mapa de distribuição dos sedimentos segundo a classificação granulométrica, da plataforma continental e talude da região sul do Rio Grande do Sul (modificado de Figueiredo e Madureira 2004). As linhas pontilhadas delimitam os diferentes tipos de sedimentos, as linhas cheias indicam a localização do canal, e a grade corresponde ao local da descontinuidade batimétrica conforme a carta náutica $N^{\circ} 90$ da $\mathrm{DHN}$.

A superfície 3D, gerada a partir dos dados batimétricos disponíveis, corresponde a uma boa representação da porção do canal do Albardão localizada na costa brasileira, uma vez que a malha amostral utilizada para a interpolação apresenta espaçamento adequado e mantém um intervalo regular de distância entre os perfis.

\section{REFERÊNCIAS}

ASEFF, CRC. 2006. Comparação de estruturas oceanográficas da Plataforma Continental do Rio Grande do Sul, Brasil, em duas situações de outono. Rio Grande, 47p. Monografia de conclusão de curso, Fundação Universidade Federal do Rio Grande.

AYUP, RN. 1987. Intercâmbio sedimentar entre o rio de la Plata exterior e a plataforma continental adjacente. Revista Pesquisas, UFRGS. 19:105-126.

CAPITOLI, RR. 2002. Distribuição e abundância dos macroinvertebrados bentônicos da plataforma continental e

\section{AGRADECIMENTOS}

Ao coordenador do Projeto PRONEX/FURG, Dr. Jorge Pablo Castello, e aos pesquisadores participantes do mesmo, Dr. José Henrique Muelbert e Dr. Osmar Möller Jr., por oportunizarem a participação da equipe de hidroacústica nos cruzeiros de pesquisa.

Ao Comandante do Navio Oceanográfico Atlântico Sul, Sr. Homero Pujeaux Alvariza, e sua tripulação.

Ao CNPq, pela concessão das bolsas de Iniciação Científica e de Doutorado, dos discentes autores deste estudo.

talude superior no extremo sul do Brasil. 173p. Tese de doutorado, Fundação Universidade Federal do Rio Grande.

COLLINS, W.; RE GREGORY \& J ANDERSON. 1996. A Digital Approach to Seabed Classification. Sea Technology, v 37, $n 8$.

CORREAA, ICS. 1987a. Sedimentos superficiais da plataforma e talude continental do Rio Grande do Sul. Revista Pesquisas, UFRGS. V 19:95-104.

CORRÊA, ICS.1987b. Plataforma continental do Rio Grande do Sul: síntese de conhecimentos. Simpósio sobre ecossistemas da costa sul e sudeste do Brasil. Cananéia. 2:50-73.

CORRÊA, ICS, LR MARTINS, JM KETZER, ARD ELIAS, \& R 
MARTINS. 1996. Evolução sedimentológica e paleogeográfica da Plataforma Continental sul e sudeste do Brasil. Notas técnicas, CECO/UFRGS, Porto Alegre-RS, Brasil. 9:51-61.

FIGUEIREDO JR, AG. \& LSP MADUREIRA. 2004. Topografia, composição, refletividade do substrato marinho e identificação das províncias sedimentares na região Sudeste-Sul do Brasil. Série documentos REVIZEE Score Sul, 64p.

FRAMIÑAN, M., 2005. On the physics, circulation and exchange processes on the Rio de La Plata estuary and the adjacent shelf. Dissertação de doutorado. University of Miami, USA, 486 p.

GRAY, JS. 1981. The ecology of marine sediments: An introduction to the structure and function of benthic communities. Cambridge Press. 184 pp.

KOWSMANN, RO. \& MPA COSTA. 1979. Sedimentação quaternária da margem continental brasileira e das áreas oceânicas adjacentes. Série Projeto REMAC (8), 55p.
LABORDE, JL. 1999. Sand deposits of the outer Rio de La Plata and adjacent continental shelf. In: Martins, LR \& Cl Santana. eds. Non living resources of the southern brazilian coastal zone and continental margin. pp.80-91

MACLENNAN, DN. \& EJ SIMMONDS. 1992. Fisheries Acoustics. Fish and Fisheries Series 5, London, Chapman \& Hall. 325p.

MARTINS, LR. 1978. Operação GEOMAR IV. Geologia Marinha. Diretoria de Hidroagrafia e Navegação, Boletim DG32-IV: 1-19, Rio de Janeiro, RJ, Brasil.

MARTINS, LR, IR MARTINS \& CM URIEN. 2003. Aspectos sedimentares da Plataforma Continental na área de influência do Rio de La Plata. GRAVEL, Porto Alegre, RS, Brasil. 1:68-80.

MITSON, RB. 1983. Fisheries Sonar. Fishing New Books LTDA. $287 p$.

SHEPARD, FP. 1979. Nomenclature based on sand-silt-clay ratios. Journal of Sedimentary Petrology, 24(3):151-158.

Recebido: 13/04/2008

Aceito: $15 / 08 / 2008$ 
